\title{
The Development and Validation of an Implicit Measure of Competence Need Satisfaction
}

\author{
Jolene van der Kaap-Deeder ${ }^{1}$ \\ Jan De Houwer ${ }^{2}$ \\ Sean Hughes ${ }^{2}$ \\ Adriaan Spruyt ${ }^{2}$ \\ Maarten Vansteenkiste ${ }^{1}$
}

In press. Motivation \& Emotion.

Correspondence can be addressed to Jolene van der Kaap-Deeder, Faculty of Psychology,

Department of Developmental, Social, and Personality Psychology, Henri Dunantlaan 2, B-9000

Ghent, Belgium. E-mail: Jolene.Deeder@UGent.be,

Tel: +3292646426. Fax: +3292646499.

${ }^{1}$ Department of Developmental, Social, and Personality Psychology, Ghent University, Ghent, Belgium.

${ }^{2}$ Department of Experimental Clinical and Health Psychology, Ghent University, Ghent, Belgium.

Jolene van der Kaap-Deeder is a Postdoctoral Fellow of the Research Foundation - Flanders.

Conflict of Interest: Author Jolene van der Kaap-Deeder declares that she has no conflict of interest. Author Jan De Houwer declares that he has no conflict of interest. Author Sean Hughes declares that he has no conflict of interest. Author Adriaan Spruyt declares that he has no conflict of interest. Author Maarten Vansteenkiste declares that he has no conflict of interest. 


\begin{abstract}
Research on Self-Determination Theory has typically relied on explicit measures when examining the concept of competence need satisfaction. As a result, we know relatively little about competence need satisfaction that arises under conditions of automaticity. Across four studies, we developed and validated implicit measures of competence need satisfaction by drawing on two tasks: a relational variant of the Implicit Association Test (IAT; Study 1, 3, and 4) and the Implicit Relational Assessment Procedure (IRAP; Study 2-3). Results across these studies revealed that both implicit measures were either unrelated or moderately related to their explicit counterpart. They were also unrelated to one another. Unlike the IRAP, the IAT was found to be reliable, to display discriminant validity, and to yield meaningful but modest relations with constructs in a nomological network. Together, these results provide modest support for the usefulness of the competence need satisfaction IAT but not of the competence need satisfaction IRAP as an implicit measure of the need for competence. Future research examining the unique predictive value of this IAT is needed, together with research on possible explanations for the low reliability of the IRAP. Key Words: Competence; Implicit Association Test; Implicit Relational Assessment Procedure; Self-Determination Theory; Implicit
\end{abstract}


Competence refers to the experience of effectiveness and mastery when interacting with the environment (White, 1959) and is a core concept in several theoretical accounts such as selfefficacy theory (Bandura, 1977), expectancy-valence theory (Atkinson \& Feather, 1966; Feather, 1992) and Self-Determination Theory (SDT; Deci \& Ryan, 2000). A notable shortcoming of past work within the SDT-tradition is the exclusive reliance on explicit measures (i.e., questionnaires) to tap into competence need satisfaction, thus precluding the benefits associated with the use of implicit measures (e.g., independence from the necessity for introspective access; Gawronski, 2009). Therefore, the aim of the present contribution was to develop and validate an implicit measure of competence need satisfaction through a series of two correlational and two experimental studies.

\section{Competence in Self-Determination Theory}

Within SDT (Deci \& Ryan, 2000; Ryan \& Deci, 2017), competence is considered (along with autonomy and relatedness) as an inherent, basic psychological need. According to the theory, psychological needs must be satisfied for people to thrive and function optimally. This claim has gained support from between-person (e.g., Ng, Lonsdale, \& Hodge, 2011) and day-to-day level studies (e.g., Ryan, Bernstein, \& Brown, 2010) showing that competence need satisfaction yields multiple benefits, including higher well-being, persistence, and performance. Such findings are evident in many life domains, ranging from work (e.g., Van den Broeck, Vansteenkiste, De Witte, Soenens, \& Lens, 2010), to school (e.g., Deci, Hodges, Pierson, \& Tomassone, 1992) and sports (e.g., Wang, Liu, Lochbaum, \& Stevenson, 2009). At the same time, feelings of competence need frustration are often associated with negative outcomes such as depressive symptoms (e.g., Bartholomew, Ntoumanis, Ryan, Bosch, \& Thøgerson-Ntoumani, 2011) and bulimic symptoms (e.g., Verstuyf, Vansteenkiste, Soenens, Boone, \& Mouratidis, 2013). 
Although the majority of researchers have focused on the satisfaction of one's need for competence, others have started to examine people's desire for competence. Need desire reflects interpersonal differences in need strength, with individuals expressing a strong desire for competence wanting to have their need for competence being met. Past work on competence desire, upon which we also rely to validate our proposed implicit measure of competence need satisfaction, has focused on two questions in particular. First, does the desire to feel competent moderate the association between competence need satisfaction and well-being? Recent evidence using selfreport measures of competence desire generally suggests this may not be the case. For instance, Chen et al. (2015) examined the well-being of individuals across four countries (i.e., Belgium, China, Peru, and USA) and found that individuals' well-being increased in-line with their experience of need satisfaction (including competence need satisfaction). Critically, however, the relation between need satisfaction and well-being was not moderated by the desire for need satisfaction, suggesting that need satisfaction is even beneficial among those who do not desire that these needs be met. Second, researchers have also examined whether a desire for competence is rooted in frustration of one's need for competence. For instance, Sheldon and Gunz (2009) found that frustration of one's psychological needs (including the need for competence) predicts a stronger desire to have these needs met, suggesting that need desire reflects deficit-based interpersonal differences in need strength (Van Assche, Van der Kaap-Deeder, Audenaert, De Schrijver, \& Vansteenkiste, in press). That is, need frustration motivates people to express a greater desire for need satisfaction, although it remains unclear whether such an enhanced desire helps them to restore their thwarted need (see also Radel, Pelletier, Sarrazin, \& Milyavskaya, 2011).

\section{Competence and Implicit Measures}


SDT-based research on competence has relied almost exclusively on direct measurement procedures like questionnaires. Because such procedures require people to self-assess psychological attributes, they depend on people's capacity for introspective access to those attributes. These measurement procedures are typically used to obtain explicit measures of psychological attributes, that is, indices of the controlled, conscious effects of psychological attributes (see De Houwer, Teige-Mocigemba, Spruyt, \& Moors, 2009, and De Houwer \& Moors, 2010, for a detailed discussion). There are, however, several reasons why measures based on introspection might fail to provide complete information (see Nosek, Hawkins, \& Frazier, 2011). For instance, people may lack the ability to introspectively access certain psychological attributes or they might be reluctant to report their introspections accurately. Because individuals might not always be willing to share their feelings of competence or might not be able to do so, alternative measures of competence need satisfaction relying on indirect procedures are valuable.

Over the past two decades, indirect measurement procedures have been proposed to obtain implicit measures of psychological attributes. Specifically, these procedures seek to capture psychological processes, attributes, or content in ways that do not depend on introspective access (De Houwer et al., 2009; De Houwer \& Moors, 2010). The implicit measures that are derived from indirect procedures aim to capture implicit (i.e., automatic) effects of psychological attributes. Implicit measures have been shown to complement explicit measures in predicting behavior, especially when behavior occurs under reduced cognitive capacity (Gawronski, 2009). For instance, Friese, Hofmann, and Wanke (2008) showed the moderating role of cognitive capacity for the predictive validity of both explicit and implicit measures with regard to individuals' attitudes towards chocolate versus fruit. Specifically, they found that the explicit measure uniquely predicted choice between a variety of fruit and chocolate bars when individuals had ample processing resources. However, only the implicit measure predicted choice behavior whenever 
individuals' processing resources were taxed. Other studies found that constructs assessed by implicit measures can moderate the effects of constructs assessed by explicit measures. For example, Gareau and Gaudreau (2017) reported that explicit autonomous motivation only related to academic achievement for individuals with a high level of implicit autonomous motivation, an effect that was maximized when individuals' working memory capacity was high.

It is worth noting that implicit measures have already been used within an implicit motive framework (e.g, McClelland, Atkinson, Clark, \& Lowell, 1953) to examine concepts related to competence. One such example is the need for achievement or the desire to be successful in achievement-related tasks (Schultheiss \& Brunstein, 2005; see also McClelland et al., 1953; Thrash \& Elliot, 2002). Unlike the competence construct in SDT, the need for achievement represents an acquired interpersonal difference variable reflecting people's dispositional tendency of wanting to excel in achievement settings. This phenomenon has mainly been assessed at the implicit level (e.g., Atkinson, 1958; Thrash \& Elliot, 2002) through the use of the Thematic Apperception Test (TAT; Murray, 1943). A typical TAT consists out of four to six pictures and requires individuals to invent a story for each picture by answering some questions (e.g., "Who are the persons on the picture?"). These written stories are then coded in terms of achievement-related content. Although the TAT has often been criticized for its poor psychometric properties (e.g., low internal consistency; Lilienfeld, Wood, \& Garb, 2000), the debate on the reliability and validity of projective measures has not yet been resolved (Hibbard, 2003).

To overcome some of the limitations associated with the TAT, researchers interested in implicit motives have increasingly turned to reaction-time measures such as the Implicit Association Test (IAT; Greenwald, McGhee, \& Schwartz, 1998). Although the IAT has mainly been used in the context of attitude research (e.g., prejudice), the IAT also proved useful to assess implicit motives, such as the motive to achieve (e.g., Brunstein \& Schmitt, 2004; Slabbinck, De 
Houwer, \& Van Kenhove, 2011). Specifically, Brunstein and Schmitt (2004) implemented an adapted IAT procedure in which individuals were presented with words related to either the self (e.g., "I") or others (e.g., "they") and words related to either success (e.g., "ambitious") or no success (e.g., "idle"). During one part of the task, participants were asked to categorize self-related and success-related words using one response key and other-related words along with nonsuccessful words using a second key. During a second part of the task, these response mappings were reversed, such that self-related and non-successful words were to be categorized using one key and other-related and success-related words using the second key. A higher score on the IAT reflected quicker responding during the first relative to the second part of the task. In their study, Brunstein and Schmitt (2004) found that IAT scores were a better predictor of performance during a mental concentration task than self-reported achievement motivation, while the latter predicted greater task enjoyment than the former. Thus, implicit measures can contribute in unique ways to research on needs and motives.

\section{Towards a Relational Perspective on Implicitly Assessed Competence Need Satisfaction}

Although the aforementioned work is certainly promising, it (potentially) suffers from one important limitation. The IAT only indicates the extent to which one set of concepts (e.g., "self" and "others") is associated with a second set of concepts (e.g., "successful" or "unsuccessful"). In this way, the IAT says little about the nature of this relation. Because the type of relation between two concepts is not specified, it becomes difficult (if not impossible) to interpret the meaning of a significant association between two constructs, an issue demonstrated in previous research on implicit self-esteem (e.g., Gemar, Segal, Sagrati, \& Kennedy, 2001). Specifically, a number of studies have found that people who were formerly depressed unexpectedly display higher implicit self-esteem than those who were never depressed (e.g., Gemar et al., 2001). In an attempt to clarify this surprising finding, Remue, De Houwer, Barnes-Holmes, Vanderhasselt, and De Raedt (2013) 
made use of the Implicit Relational Assessment Procedure (IRAP; see Vahey, Barnes-Holmes, Barnes-Holmes, \& Stewart, 2009). This task indicates how stimuli are related rather than simply assessing the strength of this relation. Specifically, they created two different IRAPs, one designed to assess actual self-evaluations (e.g., "I am" vs. "I am not" good or bad) and another designed to assess ideal self-evaluations ("I want to be" vs. "I don't want to be" good or bad). They found that participants who reported higher levels of depressive symptoms produced higher ideal selfevaluations and lower actual self-evaluations compared to their non-depressed counterparts. In sum, by specifying the exact way in which the self and success are related, it became clear that the counterintuitive observations reported by Gemar et al. (2001) resulted from differences in ideal self-evaluations rather than differences in actual self-evaluations.

A similar line of reasoning can be applied to the study of implicit motivation and needs. For example, the IAT scores reported by Brunstein and Schmitt (2004) may reflect the belief that one is successful in some individuals (which would reflect competence need satisfaction) while it may reflect the desire to be successful in other individuals (which would reflect competence need desire). Thus, categorizing one set of stimuli more quickly than another set of stimuli tells us little about the different ways how people relate those stimuli under the various conditions of automaticity. Just as the movement from interpretative (TAT) to reaction-time measures (IAT) spurred developments in research on the assessment of implicit needs, so too might relational implicit measures provide additional advantages compared to implicit measures that simply capture associative knowledge.

\section{Examining the Nomological Network}

As an important step in the validation of our proposed implicit measures of competence need satisfaction, we aimed to examine the nomological network surrounding the construct of competence need satisfaction. Indeed, as proposed by Cronbach and Meehl (1955), an important 
way to establish the construct validity of a new measurement instrument is to investigate the network of related constructs. We therefore selected a number of constructs to be part of this nomological network - namely - perfectionism, self-esteem, and contingent self-esteem.

Perfectionism. With regard to perfectionism, an important distinction is made between “evaluative concerns perfectionism" and "personal standards perfectionism" (Frost, Marten, Lahart, \& Rosenblate, 1990). Personal standards perfectionism is characterized by the setting of high personal standards (i.e., wanting to be highly competent), whereas evaluative concerns perfectionism is typified by high levels of evaluative concerns and self-criticism (i.e., doubting of competence) (e.g., Dunkley, Blankstein, Halsall, Williams, \& Winkworth, 2000). Previous studies have shown that the combination of both a high level of evaluative concerns perfectionism and personal standards perfectionism is closely related to maladaptive outcomes, such as eating disorder symptoms (Boone, Soenens, Braet, \& Goossens, 2010), stress (Rice, Ray, Davis, DeBlaere, \& Ashby, 2015), and depression (Rice \& Richardson, 2014). In contrast, a high level of personal standards perfectionism in the absence of a high degree of personal standards perfectionism, may be adaptive (e.g., Boone et al., 2010). Thus, a combination of both high personal standards and being highly critical of oneself seems to represent the most maladaptive profile. With respect to competence, Boone, Vansteenkiste, Soenens, Van der Kaap-Deeder, and Verstuyf (2014) showed that evaluative concerns perfectionism was related positively to competence frustration in adolescents. In contrast, Dunn, Dunn, and McDonald (2012) found that self-oriented perfectionism (characterized by high personal standards only) in the sports domain related to higher perceived competence with respect to sport. We therefore expected individuals with both a high level of personal standards and evaluative concerns to experience lower levels of competence satisfaction and higher levels of competence desire as compared to individuals characterized by high personal standards only. 
(Contingent) Self-esteem. Several studies have reported a positive relationship between self-esteem and competence need satisfaction. For example, Heppner, Kernis, Nezlek, Foster, Lakey, and Goldman (2008) showed that daily variation in competence need satisfaction related to daily variation in self-worth. Whereas competence need satisfaction may relate positively to overall self-worth, it may relate negatively to contingent self-esteem. Individuals are said to display a high level of contingent self-esteem when they hinge their self-esteem on meeting internal or external goals/expectations (Deci \& Ryan, 1995). The fragility of their self-worth has been found to be rooted in insecurity about personal competence (Bartholomew, Ntoumanis, Mouratidis, Katartzi, Thøgersen-Ntoumani, \& Vlachopoulos, 2018), but may also give rise to competence-frustrating experiences. Indeed, several studies have shown that an active pursuit of self-esteem relates to competency-undermining behaviors (e.g., by focusing too much on the avoidance of failure and therefore missing out on possible learning experiences) (Crocker, 2002; Van der Kaap-Deeder, Wouters, Verschueren, Briers, Deeren, \& Vansteenkiste, 2016). We anticipated a negative association between competence need satisfaction and contingent self-esteem.

\section{The Present Research}

Given the advantages and unique predictive value of implicit measures in general and the value of relational implicit measures in particular, we sought to develop and validate two new implicit (relational) measures of competence need satisfaction (i.e., a relational variant of the IAT and an IRAP). Across four studies, we set out to validate these implicit competence need satisfaction measures by (1) examining the relation between implicit and explicit measures of competence need satisfaction, (2) investigating the relation between our implicit measures and their nomological network, and (3) determining the unique predictive value of these implicit measures when explicit competence need satisfaction is controlled for. 
We forward the following hypotheses. First, although implicit and explicit measures highlight different aspects of the same phenomenon, we expected to find a small to moderate positive correlation between explicit and implicit measures of competence need satisfaction (Hoffmann, Gawronski, Gschwender, Le, \& Schmitt, 2005) (Hypothesis 1). Second, we expected that both (implicit and explicit) measures of competence need satisfaction would correlate positively with self-esteem ${ }^{1}$ and personal standards perfectionism and negatively with contingent self-esteem and evaluative concerns perfectionism (Hypothesis 2). Third, as previous research has shown that implicit measures are especially valuable when predicting behavior occurring under reduced cognitive capacity or control (Brunstein \& Schmitt, 2004; Gawronski, 2009), we expected that the implicit measures of competence need satisfaction would have unique value when predicting outcomes not obtained via questionnaires (i.e., academic grades and task performance) (Hypothesis 3). Specifically, we expected that the strength of the relations between the implicit measures of competence need satisfaction and self-reported constructs from the nomological network will diminish when explicit competence need satisfaction will be controlled for. We also anticipated that the relations between these implicit measures and objective performance would remain strong whenever explicit competence need satisfaction was taken into account. Finally, apart from these more general hypotheses, we forward a series of specific hypotheses for each of the four studies in the study-specific sections.

Our hypotheses were examined in a series of four studies, which were meant to be complimentary in nature. That is, studies differed in terms of their design (i.e., correlational vs. experimental), the type of implicit measure being used (IRAP or IAT), the included measures of the nomological network and the used validation approach (e.g., known-groups approach). We opted for this package of fairly diverse studies because they were, as a whole, supposed to provide 
convincing evidence for the validity of our new measures of implicit competence satisfaction. See also Table 1 for an overview of the characteristics of each study.

\section{Study 1}

In Study 1, we set out to examine the correlation between implicit and explicit measures of competence need satisfaction (i.e., Hypothesis 1), the relations between the implicit measure and constructs within the nomological network (i.e., Hypothesis 2), and the unique predictive value of the implicit measure with respect to constructs in the nomological network and exam grades (i.e., Hypothesis 3) in a sample of students who differed in their evaluative concerns and personal standards perfectionism. Given that previous research suggested that perceived competence is related to actual competence (e.g., Bois, Sarrazin, Brustad, Trouilloud, \& Cury, 2002), we expected a positive and unique relation between the competence need satisfaction IAT and exam grades.

As recommended for a known-groups approach (Greenwald \& Farnham), we selected individuals based on their perfectionism score by means of a cluster analysis (see method section below). The first group (personal standards condition) was comprised of those who reported high personal standards but low evaluative concerns perfectionism. The second group (evaluative concerns condition) reported high personal standards and evaluative concerns perfectionism. These two groups were created based on the assumption that they would display different levels of competence need satisfaction and desire. We expected the evaluative concerns group to score lower on satisfaction of the need for competence and higher on desire for competence compared to the personal standards group. We also expected the competence need satisfaction IAT to correlate only modestly (and negatively) to a competence need desire IAT (Hypothesis 4). Such a finding would attest to the discriminant validity of the IAT as it suggests that people can respond differently to different types of self-related statements ("I am" vs. "I desire") and that their automatic responses 
concerning competence need satisfaction cannot be equated with their automatic responses concerning competence need desire.

Note that, although we implicitly assessed competence need desire to determine the discriminant validity of the implicit measure of competence need satisfaction, we will focus on the results of the competence need satisfaction rather than the competence need desire IAT. We chose to focus on competence need satisfaction as SDT postulates that, more than the desire for competence, it is the satisfaction of this need which is most critical for individuals' well-being (Deci \& Ryan, 2000).

\section{Method}

\section{Participants}

Three hundred and ninety-seven students (315 women) between 16 and 41 years old $(M=$ 19.16; $S D=2.83$ ) at a Belgian university completed an on-line screening measure. The majority were bachelor students in psychology $(N=313)$ and were screened based on their scores on the Frost Multidimensional Perfectionism Scale (F-MPS; Frost et al., 1990). Consistent with past research in this area (e.g., Boone et al., 2010; Rice, Ashby, \& Gilman, 2011), scores on this measure were submitted to a two-step cluster analysis in order to create contrasting groups (i.e., Ward method + optimization through non-hierarchical $k$-means clustering as recommended by Gore, 2000). This led to a four-cluster solution: (1) individuals scoring low on evaluative concerns, but high on personal standards (i.e., the personal standards condition); (2) individuals with elevated scores on both variables (i.e., the evaluative concerns condition); (3) a group scoring low on both variables; and finally (4) a group who scored high on evaluative concerns but low on personal standards. Individuals belonging to the first two clusters were invited to participate in this study in exchange for course credits. Sixty-two (53 women) individuals aged between 18 and 36 years $(M$ 
$=18.92 ; S D=2.49)$ took part, with thirty-two belonging to the personal standards and thirty to the evaluative concerns condition. Most were first-year bachelor students in psychology $(n=56)$.

\section{Procedure}

Upon arrival to the laboratory, all participants were asked to provide informed consent and were tested individually. They were then provided with a cover story stating that the aim of the study was to investigate visual information processing. Thereafter, they completed the competence need satisfaction and desire IATs. The order of these IATs was counterbalanced within each group. After completing the IATs, participants completed a series of questionnaires (see self-report measures section below). Thereafter they were thanked, debriefed, and dismissed.

\section{Implicit Measures}

Competence Need Satisfaction IAT. Participants were told that their goal was to categorize words into one of four categories: "competent", "incompetent", "I am", and "I am not". Two category labels appeared on the upper left corner of the computer screen. The other two category labels appeared on the upper right side of the screen. A word could be assigned to one of the left categories by pressing the left response key (Q) or to one of the right categories by pressing the right response key (M) (on an AZERTY keyboard). Participants were also told to respond as quickly and accurately as possible. Note that this task can be considered a relational variant of the IAT given that (unlike the standard IAT) the target categories do not only contain a self-related word (i.e., "I") but also a word that specifies the relation between competence and the self (i.e., “am” and “am not”; see also De Houwer, Heider, Spruyt, Roets, \& Hughes, 2015).

We developed lexical stimuli related to competence and incompetence on the basis of the items of the competence subscale of the Basic Psychological Need Satisfaction and Need Frustration scale (BPNSNF; Chen et al., 2015), a comprehensive measure of need satisfaction and need frustration that has been validated in various countries. Stimuli for "competent" were: 
"skilled", "successful", "capable", and "able". Stimuli for "incompetent" were: "failure", "inadequate", "to fail", and "unable". The stimuli belonging to the categories "I am" and "I am not" were based on characteristics of the participant and were entered at the beginning of the IAT by the experimenter. The following stimuli were used: "human" vs. "animal”, "woman” vs. "man”, "student" vs. "employee", and "Belgian" vs. "German". Both the instructions and stimuli were presented in Dutch.

The IAT consisted of five blocks. During the first block (24 trials), participants were required to categorize incompetence-related and competence-related words by pressing the left (incompetence) or right response key (competence). In Block 2 (24 trials), participants categorized words either in the "I am" category (left key) or in the "I am not" category (right key). In the first combined block (Block 3; 96 trials) words from the "incompetent" and "I am" categories were categorized by pressing the left button whereas words belonging to the "competent" (e.g., "skilled") or "I am not" (e.g., "animal") categories were categorized using the right button. In Block 4 (24 trials) only stimuli from the competence-related categories were presented and the position of the category labels was reversed so that participants were now required to press the left button for a competence-related word and the right button for an incompetence-related word. The final block (Block 5; 96 trials) was a second combined block with "competent" and "I am" assigned to the left key and "incompetent" and "I am not" to the right key.

The stimuli that needed to be categorized were displayed in the center of a black screen in white uppercase letters (Arial font). The categories were presented in the upper corners of the screen using black bold uppercase letters (Courier font) in two (one left; one right) white filled squares. The inter-stimulus-interval was $400 \mathrm{~ms}$ and stimuli were shown randomly within each block. Errors led to the appearance of a red "X" for $400 \mathrm{~ms}$. The IAT was programmed using the INQUISIT Milliseconds software package (INQUISIT 3.0.6.0, 2011). 
Competence Need Desire IAT. The IAT assessing desire for competence was similar to that described above with a single exception: the category "I am" was replaced with "I desire", whereas the category "I am not" was replaced with "I do not desire". Stimuli for the category "I desire" were "I approach", "I want", "I strive", and "I long" and for the category "I do not desire" these were "I remove", "I avoid", "I avert", and "I obstruct". Both the instructions and stimuli were presented in Dutch.

\section{Self-report Measures}

All items were answered on a Likert scale ranging from 1 (completely not true) to 5 (completely true), unless specified otherwise.

Perfectionism. Prior to the study, a Dutch translation (Soenens, Vansteenkiste, Luyten, Duriez, \& Goossens, 2005) of the three subscales of the F-MPS was used to screen individuals for participation. Participants completed the F-MPS once again following the IATs so that we could obtain scores related to perfectionism at the time of testing. The first component of perfectionism (Personal Standards) relates to the setting of high standards and consisted of 6 items (e.g., "If I do not set the highest standards for myself, I am likely to end up a second-rate person"). This subscale showed adequate reliability $(\alpha=.73)$. The second component of perfectionism (Evaluative Concerns) was assessed by averaging scores from the Concerns over Mistakes (9 items; e.g., "People will think less of me if I make a mistake") and Doubts about Actions subscales (4 items; e.g., "It takes me a long time to do something right"). This measure showed adequate reliability ( $\alpha$ $=.86)$.

Competence Need Satisfaction. Self-reported feelings of competence were assessed using the competence subscale of the Basic Psychological Need Satisfaction and Need Frustration scale (BPNSNF; Chen et al., 2015). This subscale consisted of 8 items assessing whether the need for 
competence was satisfied (e.g., "I feel confident that I can do things well") or frustrated (e.g., "I have serious doubts about whether I can do things well"). Frustration-related items were reversed scored to obtain a relative score of competence need satisfaction. This measure showed adequate reliability $(\alpha=.89)$.

Competence Need Desire. The desire to feel competent was assessed by means of the competence-related subscale (3 items) of the Needs-as-Motives scale (Sheldon \& Gunz, 2009). People were asked to indicate how much they would like to make three competence-related changes in their life if they would have the chance to do so (e.g., "You manage to become better at some activity that is important to you, and feel less inept and incompetent"). They responded using a Likert scale ranging from 1 (no desire for this change) to 5 (much desire for this change). Cronbach's alpha was .69.

Self-Esteem. The Dutch version (Franck, De Raedt, Barbez, \& Rosseel, 2008) of the Rosenberg Self-Esteem Scale (RSES; Rosenberg, 1979) was used to assess global self-esteem. This scale consists of 10 items (e.g., "On the whole, I am satisfied with myself') that were rated on a scale ranging from 0 (strongly disagree) to 3 (strongly agree). Cronbach's alpha was .88.

Contingent Self-Esteem. Participants completed the Dutch version (Soenens \& Duriez, 2012) of the Contingent Self-esteem Scale (CSS; Paradise \& Kernis, 1999). It consists of 15 items (e.g., "I consider performing well as important for my self-esteem") and was reliable $(\alpha=.79)$.

Academic Grades. At the end of the first year of their bachelor program in psychology, participants were contacted and asked for permission to access their official academic grades. Everyone approved. We had only access to academic grades obtained by students following a bachelor in psychology, thereby excluding 6 other participants. In addition, grades from one student 
were missing. We employed the mean level of the grades (of 12 courses) in our study. Grades could range between 0 and 20 with a 10 or higher being sufficient to pass the course.

\section{Results}

\section{Descriptive Statistics and Preliminary Analyses}

Participant Exclusion. We inspected participants' responses on the IATs. Specifically, we checked whether there were participants who had a reaction time of $300 \mathrm{~ms}$ or less on at least $10 \%$ of the trials. Data from participants with such extremely fast reaction times would be deleted (in line with standard scoring algorithm for the IAT developed by Greenwald, Banaji, \& Nosek, 2003). This was not the case, such that all participants were retained in the analyses.

Manipulation Check. We first checked the validity of participants' assignment to the perfectionism profiles by examining whether perfectionism group membership was related to perfectionism scores obtained at the time of the experiment. Results of a MANOVA indicated that, as expected, individuals in the evaluative concerns perfectionistic group reported more evaluative concerns perfectionism at the time of the experiment compared to those in the personal standards perfectionistic group (see Table 2). Although less pronounced, individuals in the evaluative concerns group also reported higher levels of personal standards perfectionism than those in the personal standards group.

IATs. IAT effects were calculated using the $D 6$ measure (Greenwald et al., 2003). Latencies on error trials were replaced by the mean of the correct responses plus a penalty of $600 \mathrm{~ms}$ and the IAT effect was determined by subtracting the latencies of Block 5 (self + competent) from the latencies of Block 3 (self + incompetent). Therefore, the higher the IAT score, the stronger the belief "I am competent" (competence need satisfaction IAT) or "I desire to be competent" (competence need desire IAT). To determine the reliability of the IATs, each dataset was split into even and odd numbered trials and the $D 6$ measure was calculated for each separately. These two 
D6-measures were correlated and corrected using the Spearman-Brown formula. Split-half reliabilities were adequate for the competence need satisfaction IAT (.73) and competence need desire IAT (.69).

Background Variables. A MANCOVA was performed with gender and education (secondary vs. higher education) as fixed factors and age as a covariate when predicting all variables. As age, $F(7,42)=0.74, p>.05, \eta^{2}=.11$, gender, $F(7,42)=1.89, p>.05, \eta^{2}=.24$, and education, $F(7,42)=0.52, p>.05, \eta^{2}=.08$, were unrelated to the study variables, they were excluded from subsequent analyses.

\section{Primary Analyses}

Group Differences. As a first test of the validity of both IATs, we performed a repeated measures ANOVA to investigate whether the difference between both IATs would differ as a function of group membership (i.e., the evaluative concerns and personal standards perfectionistic group). Results showed that there was no significant difference between the scores on the two IATs in general, $F(1,60)=3.74, p=.06, \eta^{2}=.06$. However, a significant interaction did emerge between IAT type (satisfaction vs. desire) and group membership, $F(1,60)=4.35, p=.04, \eta^{2}=.07$. Followup one-way ANOVAs revealed that the perfectionism groups differed in their desire IAT scores but not in their satisfaction IAT scores. On the one hand, participants showed a (strong) relative bias for responding to one's self as competent compared to incompetent and for desiring competence rather than incompetence (as indicated by positive scores on both IATs), regardless of whether they belonged to the evaluative concerns or personal standards group. On the other hand, participants belonging to the evaluative concerns group did show a higher desire for competence than those in the personal standards group (see Table 2). 
We then performed another set of ANOVAs to investigate whether group differences would also be evident for explicit competence need satisfaction and desire (see Table 2). Results indicated that participants in the evaluative concerns group experienced less competence need satisfaction but expressed a greater desire for competence. Note that this pattern of findings is similar to that obtained with the implicit measures with a single exception: implicit competence need satisfaction did not differ significantly between the two groups.

Correlational Analyses. We performed a series of bivariate correlations to gain further insight into the validity of the competence need satisfaction IAT (see Table 3 ). ${ }^{2}$ Several findings are worth noting. First, scores on the competence need satisfaction IAT and competence need desire IAT did not correlate with one another. Second, the competence need satisfaction IAT was positively related to its explicit counterpart. Third, the competence need satisfaction IAT was positively related to self-esteem and negatively to contingent self-esteem. Also worth noting is that the associations between competence need satisfaction IAT and constructs in the nomological network were similar to the associations obtained between the explicit measure of competence need satisfaction and those same constructs. However, when we controlled for explicit competence need satisfaction, the competence need satisfaction IAT was not related to any of the study variables to a significant degree. Finally, results revealed that there was no relation between scores on the competence need satisfaction IAT and participants' mean academic grades.

\section{Discussion}

Results of Study 1 do not provide sufficient evidence for the validity of the competence need satisfaction IAT. First, we found that this implicit measure related to a moderate extent to its explicit counterpart (consistent with Hypothesis 1). Hypothesis 2 was, however, only partially confirmed as the competence need satisfaction IAT related significantly to self-esteem and contingent self-esteem but did not differ between the two perfectionistic subsamples (whereas the 
explicit measure of competence need satisfaction did). Further, we found no support for the unique predictive value of the competence need satisfaction IAT (i.e., Hypothesis 3) as it did not relate to any of the study variables once explicit competence need satisfaction was controlled for. Finally, although we expected to find a modest and negative relation between this IAT and the competence need desire IAT (i.e., Hypothesis 4), we found that these two IATs were unrelated. This indicates that participants adequately processed the propositions of both IATs and attests to the discriminant validity of the competence need satisfaction IAT.

\section{Study 2}

Study 2 was similar to Study 1 with two main differences. First, we now employed two IRAPs (rather than IATs) to assess competence need satisfaction and competence need desire implicitly. As we previously outlined, the IRAP was developed to assess how concepts are related to one another under conditions of automaticity and could therefore be more apt for capturing differences between implicit competence need satisfaction and desire (see De Houwer et al., 2015, for a more detailed discussion of the merits and limitations of relational versions of the IAT). We also tested a convenience sample of university students rather than selecting groups on the basis of their perfectionism scores (i.e., known-groups approach) given that we did not find significant differences in implicitly assessed competence need satisfaction between the perfectionism groups in our first study.

The same set of hypotheses as in Study 1 was addressed. We again examined the correlation between implicit and explicit measures of competence need satisfaction (i.e., Hypothesis 1), relations between implicit measures and constructs within the nomological network (i.e., Hypothesis 2), and the unique predictive value of implicit measures (i.e., Hypothesis 3). Additionally, we expected scores on the competence need satisfaction IRAP to relate only modestly (and negatively) to scores on a competence need desire IRAP, attesting to the discriminant validity 
of the competence need satisfaction IRAP (i.e., Hypothesis 4). Similar to Study 1, we will primarily focus on the results of the competence need satisfaction instead of the competence need desire IRAP.

\section{Method}

\section{Participants}

Sixty-seven participants (53 female) aged between 17 and 47 years old $(M=22.13 ; S D=$ 4.26) participated in exchange for 10 euro. Forty students had completed secondary education and a further twenty-seven had completed third-level education. Further, participation was voluntary and all data were processed confidentially.

\section{Procedure}

After participants gave their written consent, they received a bogus study aim to avoid disclosing the goal of the study. They were told that the aim of this study was to investigate their visual information processing. Subsequently, individuals completed the competence need satisfaction IRAP and the competence need desire IRAP. The order of these IRAPs was counterbalanced. After completing the IRAPs, participants filled out a battery of questionnaires (see further). Finally, participants were thanked, debriefed, and dismissed.

\section{Measures}

Measures identical to Study 1 were used to assess explicit competence need satisfaction ( $\alpha$ $=.87)$, explicit competence need desire $(\alpha=.55)$, perfectionism $(\alpha$ personal standards $=.87$ and $\alpha$ evaluative concerns $=.87)$, self-esteem $(\alpha=.84)$, and contingent self-esteem $(\alpha=.90)$. Besides 
these measures, we also employed a competence need satisfaction and competence need desire IRAP (see below).

Competence Need Satisfaction IRAP. Participants were informed that the goal of this task was to respond as quickly and accurately as possible in accordance with a particular response rule (even though participants themselves might not personally agree with that rule). Participants were exposed to two rules: (1) "Please respond as if I am competent and I am not incompetent" (i.e., high competence rule) and (2) "Please respond as if I am incompetent and I am not competent" (i.e., low competence rule). Participants had to indicate whether the statement presented on screen was either true or false according to the rule operating at that time by pressing the left response key (D) or the right response key (K) (on an AZERTY key board). The meaning (indicating true or false) of these response keys changed throughout the trials and appeared in the bottom left- and right-hand corners of the computer screen.

The IRAP consisted of a minimum of four practice blocks followed by six test blocks. Each block consisted of 24 trials on which one of two self-related label stimuli appeared (e.g., "I am” or "I am not") in the presence of one of the competence-related or incompetence-related target stimuli. The label and target stimuli as well as response options appeared simultaneously. Instructions and stimuli were presented in Dutch. Competence-related target stimuli were "skilled", "successful", "capable", "able", “competent", and "proficient". Incompetence-related target stimuli were "failed", "inadequate", "flunked", "unable", "incompetent", and "stupid". The combination of the two self-related label stimuli and the two (in)competence-related target stimuli created four trial types, namely self and competence (e.g., "I am" + "skilled"), not-self and incompetence (e.g., "I am not" + "failed"), self and incompetence (e.g., "I am" + "failed"), and not-self and competence (e.g., "I am not" + "skilled"). Each of the four trial types appeared six times within each block, in a random order. When the high-competence rule applied, the correct response to the first two trial- 
types was "True" and "False" for the latter two trials-types. When the low-competence rule applied, the correct responses reversed. Participants were exposed to an alternating sequence of highcompetence and low-competence rule blocks of which the first block was always a highcompetence block. Incorrect responses resulted in the presentation of a red "X", which disappeared once a correct response was selected.

During the first two practice blocks, the experimenter sat beside the participant and provided feedback when necessary. After each block, feedback was displayed indicating the accuracy and median reaction times in the previous block. However, to ensure that individuals first focused on their accuracy (to correctly learn the task), only feedback regarding participants' accuracy level was presented after the first practice block. Participants were informed that they needed to respond with greater than $80 \%$ accuracy. Then, after the second practice block, they were informed that they not only needed to obtain an accuracy level of at least $80 \%$ but also a reaction time quicker than $2000 \mathrm{~ms}$ in order to proceed to the test blocks. Failure to fulfill these criteria after four practice blocks led to the presentation of another set of four practice blocks. Participants who still failed to reach these criteria were thanked and debriefed, and their data were discarded.

Competence Need Desire IRAP. This IRAP was similar to that reported above with a single exception: the label stimuli "I am" and "I am not" were replaced with "I desire" and "I do not desire". Accordingly, participants were exposed to two rules: (1) "Please respond as if I desire to be competent and I do not desire to be incompetent" (i.e., high competence desire rule) and (2) "Please respond as if I desire to be incompetent and I do not desire to be competent" (i.e., low competence desire rule). Again, both the instructions and stimuli were in Dutch.

\section{Results}

\section{Descriptive Statistics and Preliminary Analyses}


Participant Exclusion. Four participants failed to meet mastery criteria after two sets of practice blocks on the competence need satisfaction as well as the competence need desire IRAPs. In addition, two individuals failed to maintain those same criteria during test blocks of the competence need satisfaction IRAP. Three individuals failed to maintain the criteria during test blocks of the competence need desire IRAP. And, finally, six individuals failed to meet these criteria during the test blocks of both IRAPs. We therefore excluded the data of these individuals. This left a final sample of 52 participants. ${ }^{3}$

IRAP. The IRAP effect represents the difference in time taken to respond during highcompetence relative to low-competence blocks and thus provides an index of the strength or probability of the relation between the self and competence. We calculated $D$-IRAP scores using an adaptation of Greenwald et al.'s (2003) $D$ algorithm (for details of this data transformation see Barnes-Holmes et al., 2010). For each IRAP, we calculated a single overall $D$-IRAP score where a higher score reflected a higher level of competence need satisfaction or competence need desire. ${ }^{4}$ To determine the reliability of the IRAPs, each dataset was split into even and odd numbered trials and a $D$-IRAP score computed for each. These two $D$-IRAP scores were correlated and corrected using the Spearman-Brown formula. Split-half reliabilities were low (i.e., .08) for both competence need satisfaction and competence need desire IRAP.

Background Variables. We performed a MANCOVA with gender and education (secondary vs. higher education) as fixed factors and age as a covariate in the prediction of all study variables. Age, $F(8,40)=1.16, p>.05, \eta^{2}=.19$, gender, $F(8,40)=1.63, p>.05, \eta^{2}=.25$, as well as education, $F(8,40)=0.55, p>.05, \eta^{2}=.10$, were unrelated to the study variables and were therefore excluded from subsequent analyses.

\section{Primary Analyses}


Correlational Analyses. A series of bivariate correlations were computed to provide insight into the validity of the competence need satisfaction IRAP (see Table 4). ${ }^{5}$ Several findings are of note. First, both IRAPs were unrelated to their explicit counterparts. Second, the competence need satisfaction IRAP was unrelated to personal standards perfectionism, evaluative concerns perfectionism, self-esteem, and contingent self-esteem. Third, the IRAPs correlated positively, indicating that higher levels of competence need satisfaction corresponded to higher levels of competence need desire at the implicit level.

\section{Discussion}

Results from Study 2 indicate that the competence need satisfaction IRAP is not a useful implicit measure of competence need satisfaction given that it was unrelated to its explicit counterpart (Hypothesis 1), unrelated to perfectionism, self-esteem, and contingent self-esteem (Hypotheses 2 and 3), and showed an unexpected positive relation with the competence need desire IRAP (Hypothesis 4). However, it must be noted that both IRAPs showed a very low reliability (i.e., .08), especially compared to previous studies finding reliability estimates between .23 and .81 (Gawronski \& De Houwer, 2014; Golijani-Moghaddam, Hart, Dawson, 2013). Although admittedly post-hoc, one possibility is that this low reliability is due to the use of double negations in both IRAPs, an issue we addressed in Study 3. For example, with respect to the competence need satisfaction IRAP, participants had to respond to combinations like "I am not" + "incompetent", which may have increased the difficulty of the task considerably (Hussey, Thompson, McEnteggart, Barnes-Holmes, \& Barnes-Holmes, 2015). Consequently, results of this study must be interpreted with caution.

\section{Study 3}

Study 3 set out to replicate and extend Study 2 by validating implicit measures not only in terms of the relation with their explicit counterpart and the nomological network but also in terms 
of individuals' current sense of competence. That is, we manipulated individuals' state competence experiences by exposing them to either a competence-supportive or a competence-thwarting condition. Whereas Studies 1 and 2 focused on either the competence need satisfaction IAT (Study 1) or IRAP (Study 2), in Study 3 we included both implicit measures to compare both directly. Because the IRAP was found to be unreliable in Study 2, we made several changes to the measure to rectify its poor reliability (see method section below). Similar to the previous two studies, we examined the correlation between implicit and explicit measures of competence need satisfaction (i.e., Hypothesis 1), relations between implicit measures and constructs pertaining to the preestablished nomological network (i.e., Hypothesis 2), and the unique predictive value of implicit measures, not only concerning constructs in the nomological network but also concerning task performance (i.e., Hypothesis 3). With respect to Hypothesis 3, we expected that, in line with previous studies showing a link between perceived and actual competence (e.g., Bois et al., 2002), a positive and unique relation between implicit measures of competence need satisfaction and task performance (on a computerized letter detection task) would emerge. Additionally, we also hypothesized that individuals in the competence-supportive condition would display higher levels of implicitly assessed competence need satisfaction compared to those in the competence-thwarting condition (Hypothesis 5). Finally, we expected to observe a small-to-moderate relation between the IAT and IRAP, in accordance with previous studies employing different implicit measures to assess a single construct (e.g., Schüler, Sheldon, Prentice, \& Halusic, 2016) (Hypothesis 6).

\section{Method}

\section{Participants}

One hundred and three students ( 88 female) aged between 18 and 48 years $(M=22.59 ; S D$ =4.98) completed the study in exchange for 10 euro. Fifty-three participants completed secondary education while fifty had completed higher education. 


\section{Procedure}

The study consisted of five phases: (1) priming of either competence need satisfaction or competence frustration; (2) completion of the IAT and the IRAP (task order was counterbalanced across participants); (3) assessment of momentary self-reported feelings (i.e., competence need satisfaction, personal standards perfectionism, evaluative concerns perfectionism, self-esteem, and contingent self-esteem); (4) completion of a letter-detection task to assess subjective and objective task-performance; and (5) assessment of task-related competence. At the start of the experimental session, participants gave their written consent. At the end of the session, participants received a debriefing which explained the deception of the priming manipulation. Ethical approval was obtained from the university's ethical committee. Further, participation was voluntary and all data were processed confidentially.

Priming Manipulation. Participants were assigned at random to two groups: one in which feelings of competence need satisfaction were primed $(N=52)$ and one in which frustration was primed $(N=51)$. The priming manipulation involved an adaptation of the scale manipulation task previously used by Fishbach and Dhar (2005). Specifically, in both conditions, items were rated on an atypical frequency scale ranging from 1 (never), 2 (very seldom), 3 (seldom), 4 (sometimes), to 5 (often), whereas a typical frequency scale varies from 1 (never), 2 (seldom), 3 (sometimes), 4 (often), to 5 (almost always). Due to the change in the labeling of the anchor points of the scale, participants were likely to report elevated scores. Whereas participants in the competence need satisfaction condition rated eight items concerning their competence need satisfaction (e.g., "I felt confident that I could do things well'), participants in the competence need frustration condition rated eight items concerning competence need frustration (e.g., "I had serious doubts about whether I could do things well"). The items were rated with respect to the past year (i.e., "In the past year...”). For both questionnaires, four items were taken from the Basic Psychological Need 
Satisfaction and Need Frustration scale (Chen et al., 2015). To supplement these items, we developed four additional items per questionnaire based on SDT's definition of competence. Subsequently, participants were instructed to calculate their average score on this questionnaire (a calculator was available) and to write it down. Given that they were asked to rate the items with respect to the past year and because the rating scale elicited high scores, participants were induced to report high scores of either competence need satisfaction or competence frustration. For instance, participants in the competence need satisfaction condition would likely respond to an item such as "In the past year, I felt confident that I could do things well" with a 4 (sometimes) or 5 (often).

\section{Measures}

A similar set of measures was used as in the previous studies to assess implicit competence need satisfaction (IAT), explicit competence need satisfaction $(\alpha=.89)$, perfectionism ( $\alpha$ personal standards $=.85$ and $\alpha$ evaluative concerns $=.85)$, self-esteem $(\alpha=.86)$, and contingent self-esteem $(\alpha=.86)$. Unlike Studies 1 and 2 , participants were asked to rate items with respect to how they were currently feeling (i.e., state version) rather than how they felt in general (i.e., trait version). We did so in order to assess momentary feelings following our priming manipulation. Besides these measures, we also employed a competence need satisfaction IRAP and a measure to assess taskrelated competence (see below).

Competence Need Satisfaction IRAP. The IRAP used in this study differed from the one used in Study 2 in three ways. First, different label and target stimuli were used. We now used selfrelated (i.e., "I find that", "I have the feeling that", "I think that") and others-related label stimuli (i.e., "Other people find that", "Other people have the feeling that", "Other people think that"). Six competence-related target stimuli ("I can do things well", "I am proficient in what I do", "I can achieve my goals", "I can successfully complete difficult tasks", "I am successful", and "I am 
competent") and six incompetence-related target stimuli ("I fail in the things I do", "I make a lot of mistakes", "I am a failure", "I can do nothing right", "I am not successful", and "I am incompetent") were used. This gave rise to four trial types, namely: self and competent (e.g., "I find that" + "I can do things well"), self and incompetent (e.g., "I find that" + "I fail in the things I do"), others and competent (e.g., "Other people find that" + "I can do things well"), and others and incompetent (e.g., "Other people find that" + "I fail in the things I do"). For this study, we only used the data from the first two trial types, as we were interested in the self-views of individuals rather than how they think others perceive them. ${ }^{6}$

Second, we employed two different rules as compared to the first IRAP: (1) "Please respond as if you think that you are competent and others think that you are incompetent" (i.e., high selfcompetence) and (2) "Please respond as if you think that you are incompetent and others think that you are competent" (i.e., low self-competence rule). Third, to reduce the complexity of the task, response key location was fixed across trials. Both the instructions and stimuli were in Dutch.

Letter Detection Task. To assess objective and subjective task-performance, we employed a letter-detection task (see Stoeber, Chesterman, \& Tarn, 2010). Participants were presented with a 5 x 5 array containing 25 white letters and numbers, displayed on a black computer screen. They were instructed to find the letter "E" within this array and to respond as quickly and as accurately as possible. Specifically, they were instructed to press the left response key (S) when they found the "E" and the right response key (M) when they did not find an "E". They were first presented with five practice trials followed by 100 test trials. Task performance was determined by dividing the number of correct responses by the time spent on the test trials. The letter detection task was programmed using the Affect software package (Affect 4; Spruyt, Clarysse, Vansteenwegen, Baeyens, \& Hermans, 2010). 
Task-related Competence. A subscale of the Intrinsic Motivation Inventory (Ryan, 1982;

Ryan, Koestner, \& Deci, 1991) was employed to assess participants' perceived competence with respect to the letter detection task (6 items; e.g., "I think I am pretty good at this activity"; $\alpha=.90)$. Items were rated on a scale from 1 (not at all true) to 7 (completely true).

\section{Results}

\section{Descriptive Statistics and Preliminary Analyses}

Participant Exclusion. The data of one individual did not meet the IAT-inclusion criteria. With respect to the IRAP, data of five participants were not usable as these individuals failed to fulfill the criteria after two sets of practice blocks. Regarding the test blocks of the IRAP, we observed that twenty-four individuals did not fulfill the criteria. When examining correlations with the IAT we employed the full dataset minus the participant who did not meet the IAT-inclusion criteria. When examining correlations with the IRAP we employed the full dataset minus participants who did not meet the IRAP-inclusion criteria. ${ }^{7}$

IAT and IRAP. The IAT and the IRAP effect were determined by calculating, respectively, the $D 6$ measure and the $D$-IRAP score (Greenwald et al., 2003). Whereas the split-half reliability of the IAT was adequate $(\alpha=.76)$, the IRAP demonstrated low reliability $(\alpha=.19)$ (both corrected with the Spearman-Brown formula).

Background Variables. With respect to the background variables, we performed a MANCOVA (on the dataset with both usable IAT and IRAP data) with gender and education (secondary vs. higher education) as fixed factors and age as a covariate in the prediction of all study variables. Whereas age, $F(9,61)=1.22, p>.05, \eta^{2}=.15$, and gender, $F(9,61)=1.46, p>.05$, $\eta^{2}=.18$, were unrelated to the study variables, education did show a relation with the study variables, $F(9,61)=2.51, p<.05, \eta^{2}=.27$. Specifically, participants who completed higher 
education (compared to secondary education) displayed a higher level of implicit competence need satisfaction (IAT: $F(1,69)=4.73, p<.05, \eta^{2}=.06$; IRAP: $\left.F(1,69)=7.14, p<.01, \eta^{2}=.09\right)$ and personal standards perfectionism, $F(1,69)=4.77, p<.05, \eta^{2}=.07$.

\section{Primary Analyses}

Condition Effects. First, a MANOVA (controlling for education) was used to examine whether there were differences between the competence need satisfaction and the competence need frustration condition with respect to the competence need satisfaction IAT, the competence need satisfaction IRAP, the state questionnaires, performance on the letter detection task, and taskrelated competence. A main effect of condition emerged on these variables, both in the dataset with participants with a usable IAT score, $F(9,85)=2.16, p<.05, \eta^{2}=.19$, as well as in the dataset with participants with a usable IRAP score, $F(9,62)=2.24, p<.01, \eta^{2}=.25$. Participants in the competence need satisfaction condition had a higher competence need satisfaction IRAP score and felt more competent over their performance during the letter detection task. There were no other significant differences between the two conditions, including the IAT scores (see Table 5).

Correlational Analyses. Bivariate correlations were carried out to investigate the relation between the implicit measures and the other study variables. As displayed in Table $6^{8}$, the competence need satisfaction IAT correlated positively with state competence need satisfaction and state self-esteem, whereas the competence need satisfaction IRAP correlated negatively with state evaluative concerns perfectionism. When we controlled for explicit competence need satisfaction, (a) the competence need satisfaction IAT was unrelated to each of the study variables but (b) the relation between competence need satisfaction IRAP and evaluative concerns perfectionism did remain significant. Both implicit measures were unrelated to one another.

\section{Discussion}


Once again, we failed to observe strong evidence for the usefulness of the IAT or IRAP as implicit measures of competence need satisfaction. Hypothesis 1 was partially confirmed as the competence need satisfaction IAT (unlike the IRAP) did relate to explicit competence need satisfaction. Hypothesis 2 was also partially confirmed: the IAT was related to self-esteem and the IRAP was related to evaluative concerns perfectionism. Only this latter relation remained significant after controlling for explicit competence need satisfaction, thereby partially confirming Hypothesis 3. Hypothesis 5 was confirmed only for the IRAP, as participants in the competence need satisfaction condition displayed a higher IRAP score than individuals in the competence need frustration condition. We found both implicit measures to be unrelated, which is inconsistent with Hypothesis 6. Finally, whereas the reliability of the IAT was adequate, the IRAP showed poor reliability.

Thus, in general, we found little support for our hypotheses. Although the results of the IRAP are in line with the non-supportive findings of Study 2 (perhaps, again, due to the low reliability), the results concerning the IAT obtained in the current study were less convincing than those obtained in Study 1. This might be due to the employed manipulation not being strong enough to have an effect on this IAT.

\section{Study 4}

Similar to Study 3, we also aimed to validate the competence need satisfaction IAT by inducing either feelings of success or feelings of failure. Note that in Study 3 we did not find differences in the IAT scores between the two conditions after a subtle manipulation competence. Therefore, we now made use of a more explicit manipulation of competence-related feelings. We only focused on the competence need satisfaction IAT and not the IRAP given that the latter measure was found to be substantially less reliable than the former and the fact that the IAT effect showed more relevant correlations with related constructs. 
We examined the correlation between implicit and explicit measures of competence need satisfaction (i.e., Hypothesis 1), relation between the implicit measure and self-esteem (one of the constructs within the nomological network) (i.e., Hypothesis 2), and the unique predictive value of the implicit measure concerning not only self-esteem but also task-related competence (i.e., Hypothesis 3). With respect to Hypothesis 3, we expected that IAT scores would positively relate to task-related competence. We also hypothesized that those in the competence need satisfaction condition would display higher levels of implicitly assessed competence need satisfaction compared to their counterparts in the competence need frustration condition (Hypothesis 5).

\section{Method}

\section{Participants}

Seventy-two participants (51 female) aged between 17 and 50 years $(M=19.54 ; S D=3.92)$ completed the study in return for course credits. The majority of those were first year psychology students $(n=59)$.

\section{Procedure}

At the start of the study, participants gave their written consent. Participation was voluntary and all data were processed confidentially. The study consisted of three phases: (1) an assessment of demographic information, (2) a puzzle task to induce feelings of competence satisfaction or competence frustration, and (3) questionnaires concerning momentary feelings. With respect to the puzzle task, participants were randomly assigned to either the competence need satisfaction $(N=$ 36) or the competence need frustration $(N=36)$ condition. In both conditions, the puzzle task was described as a test of competence with regard to visual information processing as to increase the likelihood that experiencing success or failure with regard to this task would impact participants' feelings of (in)competence. 
The Tangram Puzzle Task. The Tangram Puzzle Task (TPT) consists of seven geometrically different pieces that need to be assembled correctly to form specific homogeneous figures. The experimenter informed participants about the task and demonstrated how to assemble the pieces to form a specific figure. Subsequently, participants started with the practice phase in which they were given four minutes to assemble two figures (one easy and one difficult figure). During the test phase, participants were required to solve five puzzles within ten minutes. A competence need satisfaction and competence need frustration condition were created by varying (1) the standard of success and (2) the level of difficulty of the figures. In both conditions individuals were informed that $50 \%$ of their peers could, respectively, correctly assemble two (competence need satisfaction condition) or four (competence need frustration condition) puzzles within the time limit. The puzzle figures were more difficult in the competence need frustration condition as compared to the competence need satisfaction condition, adding further to the likelihood of failing to attain the communicated standard (i.e., $50 \%$ of their peers solving four puzzles). During both the practice and the test phase, participants were asked to write down whether they had successfully assembled a puzzle before continuing to the next puzzle. We adopted this approach to make the success or failure experience as salient as possible. The puzzle reports themselves were not used in the study. Before the test phase (and after the practice phase), the experimenter left the room and observed participants through a one-way mirror. Then, after the test phase, she re-entered the room and provided participants with condition-specific feedback. Finally, participants were then asked to complete a set of questionnaires and were thanked, debriefed, and dismissed.

Measures. Measures identical to Studies 1-3 were used to assess implicit competence need satisfaction (IAT; $\alpha=.80)$, explicit competence need satisfaction $(\alpha=.88)$, and self-esteem $(\alpha=$ .89). Once again, participants were asked to rate items with respect to how they were currently 
feeling (i.e., state version) rather than how they felt in general (i.e., trait version). Whereas selfesteem was previously rated on a 4-point scale, participants now rated the items on a 10-point scale to have a more sensitive assessment of their current self-evaluations. Questionnaires were administered after the puzzle task. Besides these measures, we also employed a measure to assess task-related competence (see below).

Puzzle Task-related Competence. A subscale of the Intrinsic Motivation Inventory (Ryan, 1982; Ryan et al., 1991) was employed to assess perceived competence with respect to the puzzle task (2 items; e.g., "I think I knew well how I could make the puzzles"; $\alpha=.84)$. Items were rated on a scale from 1 (not at all true) to 7 (completely true).

\section{Results}

\section{Descriptive Statistics and Preliminary Analyses}

Participant Exclusion. All participants met the IAT-inclusion criteria.

IAT. The IAT effect was determined by calculating the D6 measure (Greenwald et al., 2003).

Background Variables. With respect to the background variables, we performed a MANCOVA with gender as a fixed factor and age as a covariate in the prediction of all study variables. Both gender, $F(4,65)=1.26, p>.05, \eta^{2}=.07$, and age, $F(4,65)=1.98, p>.05, \eta^{2}=.11$, were unrelated to study variables.

\section{Primary Analyses}

Condition Effects. MANCOVA analyses examined whether there were differences between competence need satisfaction and frustration conditions in the scores on the competence need satisfaction IAT and state questionnaires (i.e., puzzle-task related competence, competence need satisfaction, and self-esteem). A main effect of condition emerged on these variables, $F(4$, 
$66)=17.38, p<.001, \eta^{2}=.51$. Subsequently, however, we only found a significant difference between the two conditions with regard to puzzle task-related competence (but not with regard to the competence need satisfaction IAT), such that participants in the competence need satisfaction condition displayed a higher level of puzzle task-related competence (see Table 7).

Correlational Analyses. Subsequently, we investigated the relation between the competence need satisfaction IAT and the other study variables by means of bivariate correlations. As displayed in Table 8, the competence need satisfaction IAT was unrelated to all other variables. The same pattern was observed when controlling for explicit competence need satisfaction. Explicit competence need satisfaction was positively related to self-esteem.

\section{Discussion}

We found no evidence for the usefulness of the competence need satisfaction IAT, as it was unrelated to its explicit counterpart (conflicting with Hypothesis 1), unrelated to self-esteem (conflicting with Hypotheses 2 and 3), and did not differ between the two conditions (conflicting with Hypothesis 5). This latter finding is congruent with Study 3 in which we also found no condition-differences with respect to the IAT. Similar to Study 1 and 3, we did find the IAT to show an acceptable level of internal consistency.

\section{General Discussion}

Across four studies we set out to develop and validate an implicit measure of competence need satisfaction. This aim was pursued by (a) relating implicit measures to their explicit counterparts; (b) investigating the relation between implicit measures and relevant variables in a nomological network; and (c) examining the unique predictive value of implicit measures. We developed both a competence need satisfaction relational IAT and a competence need satisfaction IRAP and made use of both correlational and experimental methods to provide complimentary evidence for the validity of the implicit measures. Overall, the findings turned out to be rather 
disappointing: they provide some evidence for the reliability and validity of the competence need satisfaction IAT, but no evidence for the unique predictive value of this measure. The competence need satisfaction IRAP was unreliable and insufficiently valid, although this measure was more sensitive to state changes in competence need satisfaction than the IAT.

\section{Relations between Implicit Measures and their Explicit Counterparts}

In line with Hypothesis 1, we found some evidence for an association between the implicit and explicit measures of competence need satisfaction, yet only for the IAT measure. A significant correlation was obtained in Studies 1 and 3 but not in Study 4. The size of the correlations (i.e., .31 and .27 , respectively) in these first two studies was comparable with the mean correlation of .24 between the IAT and its explicit counterpart as found in a meta-analysis by Hoffmann et al. (2005). With respect to the competence need satisfaction IRAP, there was no relation with its explicit counterparts in Studies 2 and 3. One way to account for this observation concerns the poor reliability of the measure. Indeed, the low reliability of the IRAP has been described as a major shortcoming, which also limits the validity of the measure (see also Golijani-Moghaddam et al., 2013).

Another possible reason for why we found the IRAP to be unrelated to its explicit counterpart may be that there was possibly less conceptual overlap between the IRAP and the explicit measure as compared to the overlap between the IAT and its explicit counterpart (Hoffmann et al., 2005). This would be especially true for the IRAP used in Study 3. That is, while the IRAP in Study 2 (similar to the IAT and the explicit measure of competence need satisfaction) included self-related statements only (e.g., the high competence rule "Please respond as if I am competent and I am not incompetent"), the IRAP in Study 3 included both self- and other-related statements (e.g., the high competence rule "Please respond as if you think that you are competent and others think that you are incompetent"). We deliberately implemented this adaptation to avoid 
using statements with double negations (see above), but it also made the IRAP less similar to the other measures concerning competence need satisfaction. Finally, the non-significant association between the IRAP and its explicit counterpart could be due to effects of moderator variables. That is, the congruency between both measures might be higher for some individuals with certain characteristics (e.g., a higher level of self-determination, Thrash, Maruskin, \& Martin, 2012).

\section{Relation with the Nomological Network}

With regard to Hypothesis 2, we expected both implicit measures of competence need satisfaction to show meaningful relations with other concepts in the nomological network of competence. We found that the competence need satisfaction IAT related to indicators of selfesteem in Studies 1 and 3, but not in Study 4. Whereas IAT scores correlated negatively with contingent self-esteem in Study 1, there was no relation between the two in Study 3. Across the studies, the IAT was unrelated to both personal standards and evaluative concerns perfectionism. Additionally, we found no relation between the IAT and academic grades (Study 1) or performance on a letter detection task (Study 3). In short, the competence need satisfaction IAT was related only to self-esteem indicators. One possibility is that competence need satisfaction is, at a conceptual level, more closely related to self-esteem than to perfectionism or objective performance. Indeed, previous research has pointed out that competence or evaluating oneself as powerful and effective is an important dimension of self-esteem (Tafarodi \& Swann, 1995).

With respect to the unique predictive value of implicit competence need satisfaction (i.e., Hypothesis 3), we found that the obtained correlations between the competence need satisfaction IAT and the other study variables dropped to non-significance when controlling for explicit competence need satisfaction. These findings indicate that the competence need satisfaction IAT does not yield unique predictive power and that the explicit measure is the best predictor in this case. Note, however, that we assessed mostly self-reported constructs of which, based on previous 
studies (e.g., Friese et al., 2008), explicit measures (such as our competence need satisfaction questionnaire) are likely to be more predictive than implicit measures (such as our competence need satisfaction IAT). That is, both our explicit measure of competence need satisfaction as well as the self-reported constructs are more susceptible to individuals' cognitive control, whereas implicit measures are expected to relate more to measures of behavior occurring under reduced cognitive capacity (Gawronski, 2009).

As for the competence need satisfaction IRAP, the obtained correlations with constructs of the nomological network were even more disappointing than those observed for the competence need satisfaction IAT. Specifically, the IRAP only related to evaluative concerns perfectionism in Study 3, but this relation did remain significant when controlling for explicit competence need satisfaction (thereby providing supporting evidence for Hypothesis 3). There were no significant relations between the IRAP and self-esteem, contingent self-esteem, personal standards perfectionism, and performance in Study 2 and 3. This might be due to the competence need satisfaction IRAP not accurately or fully assessing the concept of competence, or due to the low reliability of the measure.

\section{Discriminant Validity of Implicit Competence Need Satisfaction Measures}

We aimed to tap into the satisfaction of the need for competence rather than the mere presence of an association between feelings of competence and the self. Specifically, we examined whether participants can discriminate between propositions reflecting satisfaction of the need for competence (i.e., "I am competent" vs. "I am incompetent") and propositions reflecting a desire for competence (i.e., "I desire to be competent" vs. "I desire to be incompetent"). Attesting to the discriminant validity of the IAT, Study 1 showed that findings of the competence need satisfaction and competence need desire IAT did not parallel each other. Most importantly in this regard, whereas individuals in the evaluative concerns perfectionistic group revealed a stronger implicit 
desire than individuals in the personal standards perfectionistic group, these groups did not differ with regard to their score on implicit competence need satisfaction. This finding is in line with that of Remue et al. (2013) who showed that dysphoric individuals responded differently to two implicit measures differing only with respect to the employed propositions (i.e., "I am" vs. "I want to be"). With respect to Hypothesis 4, we expected the implicit measures of competence need satisfaction to relate modestly and negatively to the implicit measures of competence need desire. Although we found the IAT variants to be unrelated, the correlation between competence need satisfaction IRAP and the desire IRAP was positive rather than negative. This is in contrast with previous research showing competence need desire to be related to competence frustration (Sheldon \& Gunz, 2009). Possibly, the strength of the relation between both IRAPs is inflated due to the use of a similar method (i.e., the IRAP), an issue that could be especially salient due to the strict performance criteria of the IRAP which increases the risk of mostly assessing method variance. Thus, although we found initial evidence for the discriminant validity of the competence need satisfaction IAT, this was not the case for the competence need satisfaction IRAP.

\section{A Possible Differentiation between the Competence Need Satisfaction IAT and IRAP}

With regard to Hypothesis 5, we expected both implicit measures of competence need satisfaction to be influenced by momentary feelings of competence. Therefore, in Studies 3 and 4, we manipulated competence feelings, either in a subtle (through a priming task) or strong manner (through a puzzle task). Whereas the IRAP revealed an effect of this manipulation in the expected direction (Study 3), this was not the case for the IAT. Based on these findings, we argue that the competence need satisfaction IRAP is more sensitive to changes in individuals' situational feelings than the competence need satisfaction IAT. Perhaps, the IRAP could be regarded more as a state measure of competence need satisfaction and the IAT more as a trait measure, which seems to correspond to the stronger relation between the IAT and trait measures of constructs in the 
nomological network. This could also explain why the IAT and IRAP were found to be unrelated in Study 3, which was not in line with the small to moderate positive relation we initially expected (in line with Hypothesis 6). Future research is needed to test this idea.

\section{Limitations}

The current studies have several limitations. First, the sample sizes were relatively small and consisted of (mostly female) university students. This potentially limits the generalizability of our findings. Future research should examine the validity of the implicit measures of competence using larger and more heterogeneous samples of participants differing in relevant sociodemographic characteristics such as age, sex, level of education, and cultural background. We must also note that the observed significant relations need to be interpreted with caution as we ran, across all four studies, multiple analyses which increases the probability of type-I errors. All studies made use of a cross-sectional design, either experimental or non-experimental, thereby shedding no light on the dynamics of implicitly assessed competence over time (e.g., to investigate the stability across time of implicit competence need satisfaction). Finally, we included a rather limited set of constructs related to the nomological network of competence (i.e., personal standards and evaluative concerns perfectionism, self-esteem, and contingent self-esteem). Perhaps other competence-related constructs (e.g., self-efficacy) would have shown a stronger relation with the implicit measures of competence need satisfaction.

\section{Directions for Future Research}

Future studies could build on our results in several ways. First, there is a need for further validation of the competence need satisfaction IAT by further exploring its predictive validity. Previous research has shown that implicit measures are especially valuable when predicting behavior occurring under reduced cognitive capacity (Gawronski, 2009). Therefore, it would be interesting to investigate the value of the competence need satisfaction IAT in predicting 
spontaneous behaviors (i.e., behaviors executed without much executive control) or behaviors that are conducted under pressure. Asendorpf, Banse, and Mucke (2002) found an IAT measuring shyness to predict spontaneous/uncontrolled behaviors of shyness (e.g., tensed body) but not controlled behaviors of shyness (e.g., speech). Brunstein and Schmitt (2004) found that an IAT measuring achievement motivation predicted test performance. Taking a broader perspective, one might expect that the competence need satisfaction IAT has unique value when it comes to predicting behaviors in clinical groups characterized by lower levels of cognitive control (e.g., individuals with a substance abuse disorder).

Previous studies have found the relation between explicit competence satisfaction and domain-specific outcomes (e.g., academic goal motivation) to be stronger for individuals with a strong need for achievement (e.g., Schüler, Sheldon, \& Fröhlich, 2010). It would be interesting for future studies to investigate whether this moderating role of the need for achievement also applies to the relation between implicit competence satisfaction and well-being.

Future studies could also focus on adapting the competence need satisfaction IAT to specific domains. In our work, we used the measure to assess general competence. Yet results indicate that this IAT did not relate to domain-specific competence (i.e., academic competence). Future studies could therefore adapt the competence need satisfaction IAT to assess domainspecific competencies. Additionally, future studies could expand the relational IAT approach to the other two basic psychological needs as proposed by SDT (Deci \& Ryan, 2000), that is, relatedness and autonomy. Although past research has examined these concepts using the IAT (e.g., Keatley, Clarke, \& Hagger, 2012), propositions have not been incorporated in such IATs. Based on the results of the present study and the study by Remue et al. (2013), this could have an important additional value in SDT research. 
Finally, more research is needed on possible explanations for the low reliability of the IRAP and on how this reliability can be improved. In this respect, it would be interesting to examine constructs that might moderate the reliability of the IRAP (Golijani-Moghaddam et al., 2013), thereby focusing on both person characteristics (e.g., cognitive capabilities) as well as contextual factors (e.g., the salience of the assessed construct).

\section{Conclusion}

Across four studies, we failed to obtain substantial support for the usefulness of the competence need satisfaction IAT or IRAP. Although the IAT was reliable and displayed discriminant validity, it did not relate in a systematic way to its explicit counterparts or theoretically-related constructs, with the exception of self-esteem. It was also not influenced by competence-related manipulations. The IRAP, in contrast, did show variations as a function of such manipulations at the group level, but it produced scores that were unreliable, related only to evaluative concerns perfectionism, and showed insufficient discriminant validity. Both measures (with one exception for the IRAP in Study 3) had no unique relations with other competence-related constructs when controlling for explicit competence need satisfaction. As such, it seems that - at this point - we do not have a sufficiently useful implicit measure of competence need satisfaction. 


\section{Compliance with Ethical Standards}

Funding: Preparation of this paper was supported by Grant $12 \mathrm{X} 5818 \mathrm{~N}$ of the Research Foundation - Flanders and Methusalem Grant BOF16/MET_V/002 of Ghent University.

Ethical approval: This article does not contain any studies with animals performed by any of the authors.

Ethical approval: All procedures performed in studies involving human participants were in accordance with the ethical standards of the institutional and/or national research committee and with the 1964 Helsinki declaration and its later amendments or comparable ethical standards.

Informed consent: Informed consent was obtained from all individual participants included in the study. 


\section{References}

Asendorpf, J. B., Banse, R., \& Mucke, D. (2002). Double dissociation between implicit and explicit personality self-concept: The case of shy behavior. Journal of Personality and Social Psychology, 83, 380-393. doi: 10.1037//0022-3514.83.2.380

Atkinson, J. W. (Ed.) (1958). Motives in fantasy, action, and society: A method of assessment and study. New York: Van Nostrand.

Atkinson, J. W., \& Feather, N. (1966). A theory of achievement motivation. New York: Wiley and Sons.

Bandura, A. (1977). Self-efficacy: Toward a unifying theory of behavioral change. Psychological Review, 84, 191-215. doi: 10.1016/0146-6402(78)90002-4

Barnes-Holmes, D., Barnes-Holmes, Y., Stewart, I., \& Boles, S. (2010). A sketch of the Implicit Relational Assessment Procedure (IRAP) and the Relational Elaboration and Coherence (REC) model. The Psychological Record, 60, 527-542.

Bartholomew, K. J., Ntoumanis, N., Mouratidis, A., Katartzi, E., Thøgersen-Ntoumani, C., \& Vlachopoulos, S. (2018). Beware of your teaching style: A school-year long investigation of controlling teaching and student motivational experiences. Learning and Instruction, 53, 50-63. doi: 10.1016/j.learninstruc.2017.07.006

Bartholomew, K. J., Ntoumanis, N., Ryan, R. M., Bosch, J. A., \& Thøgersen-Ntoumani, C. (2011). Self-Determination Theory and diminished functioning: The role of interpersonal control and psychological need thwarting. Personality and Social Psychology Bulletin, 37, 1459-1473. doi: 10.1177/0146167211413125

Boone, L., Soenens, B., Braet, C., \& Goossens, L. (2010). An empirical typology of perfectionism in early-to-mid adolescents and its relation with eating disorder symptoms. Behaviour Research and Therapy, 48, 686-691. doi: 10.1016/j.brat.2010.03.022 
Boone, L., Vansteenkiste, M., Soenens, B., Van der Kaap-Deeder, J., \& Verstuyf, J. (2014). Selfcritical perfectionism and binge eating symptoms: A longitudinal test of the intervening role of psychological need frustration. Journal of Counseling Psychology, 61, 363-373. doi: $10.1037 / \mathrm{a} 0036418$

Bois, J. E., Sarrazin, P. G., Brustad, R. J., Trouilloud, D. O., \& Cury, F. (2002). Mothers' expectancies and young adolescents' perceived physical competence: A yearlong study. Journal of Early Adolescence, 22, 384-406. doi: 10.1177/027243102237189

Brunstein, J. C., \& Schmitt, C. H. (2004). Assessing individual differences in achievement motivation with the Implicit Association Test. Journal of Research in Personality, 38, 536-555. doi: 10.1016/j.jrp.2004.01.003

Chen, B., Vansteenkiste, M., Beyers, W., Boone, L., Deci, E. L., Van der Kaap-Deeder, J., et al. (2015). Basic psychological need satisfaction, need frustration, and need strength across four cultures. Motivation and Emotion, 39, 216-236. doi: 10.1007/s11031-014-9450-1

Cronbach, L. J., \& Meehl, P. E. (1955). Construct validity in psychological tests. Psychological Bulletin, 52, 281-302. doi: 10.1037/h0040957

Crocker, J. (2002). The costs of seeking self-esteem. Journal of Social Issues, 58, 597-615. doi: $10.1111 / 1540-4560.00279$

Deci, E. L., Hodges, R., Pierson, L., \& Tomassone, J. (1992). Autonomy and competence as motivational factors in students with learning disabilities and emotional handicaps. Journal of Learning Disabilities, 25, 457-471. doi: 10.1177/002221949202500706

Deci, E. L., \& Ryan, R. M. (1995). Human agency: The basis for true self-esteem. In M. H. Kernis (Ed.), Efficacy, agency, and self-esteem (pp. 31-50). New York: Plenum.

Deci, E. L., \& Ryan, R. M. (2000). The 'what' and 'why' of goal pursuits: Human needs and the self-determination of behavior. Psychological Inquiry, 11, 227-268. 
doi:10.1207/S15327965PLI1104_01

De Houwer, J. (2014). A propositional model of implicit evaluation. Social and Personality Psychology Compass, 8, 342-353. doi: 10.1111/spc3.12111

De Houwer, J., Heider, N., Spruyt, A., Roets, A., \& Hughes, S. (2015). The relational responding task: toward a new implicit measure of beliefs. Frontiers in Psychology, 6, 319. doi: 10.3389/fpsyg.2015.00319

De Houwer, J., \& Moors, A. (2010). Implicit measures: Similarities and differences. In B. Gawronski, \& B. K. Payne (Eds.), Handbook of implicit social cognition: Measurement, theory, and applications (pp. 176-193). New York, NY: Guilford Press.

De Houwer, J., Teige-Mocigemba, S., Spruyt, A., \& Moors, A. (2009). Implicit measures: A normative analysis and review. Psychological Bulletin, 135, 347-368. doi: $10.1037 / \mathrm{a} 0014211$

Dwyer, L. A., Hornsey, M. J., Smith, L. G. E., Oei, T. P. S., \& Dingle, G. A. (2011). Participant autonomy in cognitive behavioral group therapy: An integration of self-determination and cognitive behavioral theories. Journal of Social and Clinical Psychology, 30, 24-46. doi: $10.1521 /$ jscp.2011.30.1.24

Dunkley, D. M ., Blankstein, K. R., Halsall, J., Williams, M., \& Winkworth, G. (2000). The relation between perfectionism and distress: Hassles, coping, and perceived social support as mediators and moderators. Journal of Counseling Psychology, 47, 437-453. doi: 10.1037//0022-0167.47.4.437

Dunn, J. G. H., Dunn, J. C., \& McDonald, K. (2012). Domain-specific perfectionism in intercollegiate athletes: Relationships with perceived competence and perceived importance in sport and school. Psychology of Sport and Exercise, 13, 747-755. doi: 10.1016/j.psychsport.2012.05.002 
Feather, N. T. (1992). Values, valences, expectations, and actions. Journal of Social Issues, 48, 109-124. doi: 10.1111/j.1540-4560.1992.tb00887.x

Fishbach, A., \& Dhar, R. (2005). Goals as excuses or guides: The liberating effect of perceived goal progress on choice. Journal of Consumer Research, 32, 370-377. doi:

$10.1086 / 497548$

Franck, E., De Raedt, R., Barbez, C., \& Rosseel, Y. (2008). Psychometric properties of the Dutch Rosenberg Self-Esteem Scale. Psychologica Belgica, 48, 25-35.

Friese, M., Hofmann, W., \& Wanke, M. (2008). When impulses take over: Moderated predictive validity of explicit and implicit attitude measures in predicting food choice and consumption behavior. British Journal of Social Psychology, 47, 397-419. doi: $10.1348 / 014466607 X 241540$

Frost, R. O., Marten, P., Lahart, C., \& Rosenblate, R. (1990). The dimensions of perfectionism. Cognitive Therapy and Research, 14, 449-468. doi: 10.1007/BF01172967

Gareau, A., \& Gaudreau, P. (2017). Working memory moderates the effect of the integrative process of implicit and explicit autonomous motivation on academic achievement. British Journal of Psychology, 108, 701-720. doi: 10.1111/bjop.12239

Gawronski, B. (2009). Ten frequently asked questions about implicit measures and their frequently supposed, but not entirely correct answers. Canadian Psychology, 50, 141150. doi: $10.1037 / \mathrm{a} 0013848$

Gawronski, B., \& De Houwer, J. (2014). Implicit measures in social and personality psychology. In H. T. Reis, \& C. M. Judd (Eds.), Handbook of research methods in social and personality psychology (2nd edition, pp. 283-310). New York, NY: Cambridge University Press.

Gemar, M. C., Segal, Z. V., Sagrati, S., \& Kennedy, S. J. (2001). Mood-induced changes on the 
implicit association test in recovered depressed patients. Journal of Abnormal

Psychology, 110, 282-289. doi: 10.1037//0021-843X.110.2.282

Golijani-Moghaddam, N., Hart, A., Dawson, D. L. (2013). The Implicit Relational Assessment Procedure: Emerging reliability and validity data. Journal of Contextual Behavioral Science, 2, 105-119.

Gore, P. A. (2000). Cluster analysis. In H. E. A. Tinsley \& S. D. Brown (Eds.), Handbook of applied multivariate statistics and mathematical modeling (pp. 297-321). San Diego, CA: Academic Press.

Greenwald, A. G., Banaji, M. R., \& Nosek, B. A. (2003). Understanding and using the Implicit Association Test: I. An improved scoring algorithm. Journal of Personality and Social Psychology, 85, 197-216. doi: 10.1037/0022-3514.85.2.197

Greenwald, A. G, \& Farnham, S. D. (2000). Using the Implicit Association Test to measure selfesteem and self-concept. Journal of Personality and Social Psychology, 79, 1022-1038. doi: 10.1037/0022-3514.79.6.1022

Greenwald, A. G., McGhee, D. E., \& Schwartz, J. L. K. (1998). Measuring individual differences in implicit cognition: The implicit association test. Journal of Personality and Social Psychology, 74, 1464-1480. doi: 10.1037/0022-3514.74.6.1464

Heppner, W. L., Kernis, M. H., Nezlek, J. B., Foster, J., Lakey, C. E., \& Goldman, B. M. (2008). Within-person relationships among daily self-esteem, need satisfaction, and authenticity. Psychological Science, 19, 1140-1145. doi: 10.1111/j.1467-9280.2008.02215.x

Hibbard, S. (2003). A critique of Lilienfeld et al.'s (2000) "The Scientific Status of Projective Techniques". Journal of Personality Assessment, 80, 260-271. doi: 10.1207/S15327752JPA8003_05

Hoffmann, W., Gawronski, B., Gschwender, T., Le, H., \& Schmitt, M. (2005). A meta-analysis 
on the correlation between the implicit association test and explicit self-report measures. Personality and Social Psychology Bulletin, 31, 1369-1385. doi: $10.1177 / 0146167205275613$

Hughes, S., Barnes-Holmes, D., \& De Houwer, J. (2011). The dominance of associative theorizing in implicit attitude research: Propositional and behavioral alternatives. Psychological record, 61, 465-496.

Hussey, I., Thompson, M., McEnteggart, C., Barnes-Holmes, D., \& Barnes-Holmes, Y. (2015). Interpreting and inverting with less cursing: A guide to interpreting IRAP data. Journal of Contextual Behavioral Science, 4, 157-162. doi: 10.1016/j.jcbs.2015.05.001

Keatley, D., Clarke, D. D., \& Hagger, M. S. (2012). Investigating the predictive validity of implicit and explicit measures of motivation in problem-solving behavioural tasks. British Journal of Social Psychology. doi: 10.1111/j.2044-8309.2012.02107.x

Lilienfeld, S. O., Wood, J. M., \& Garb, H. N. (2000). The scientific status of projective techniques. Psychological Science in the Public Interest, 1, 27-66.

McClelland, D. C., Atkinson, J. W., Clark, R. A., \& Lowell, E. L. (1953). The achievement motive. New York: Appleton-Century-Crofts.

Murray, H. A. (1943). Thematic Apperception Test manual. Cambridge, MA: Harvard University Press.

Ng, J. Y. Y., Lonsdale, C., \& Hodge, K. (2011). The Basic Needs Satisfaction in Sport Scale (BNSSS): Instrument development and initial validity evidence. Psychology of Sport and Exercise, 12, 257-264. doi: 10.1016/j.psychsport.2010.10.006

Paradise, A. W., \& Kernis, M. H. (1999). Development of the Contingent Self-Esteem Scale. Unpublished scale, University of Georgia.

Radel, R., Pelletier, L. G., Sarrazin, P., \& Milyavskaya, M. (2011). Restoration process of the 
need for autonomy: The early alarm stage. Journal of Personality and Social Psychology, 101, 919-934. doi: 10.1037/a0025196

Remue, J., De Houwer, J., Barnes-Holmes, D., Vanderhasselt, M., \& De Raedt, R. (2013). Selfesteem revisited: Performance on the implicit relational assessment procedure as a measure of self- versus ideal self-related cognitions in dysphoria. Cognition \& Emotion, 27, 1441-1449.

Rice, K. G., Ashby, J. S., \& Gilman, R. (2011). Classifying adolescent perfectionists. Psychological Assessment, 23, 563-577. doi: 10.1037/a0022482

Rice, K. G., Ray, M. E., Davis, D. E., DeBlaere, C., \& Ashby, J. S. (2015). Perfectionism and longitudinal patterns of stress for STEM majors: Implications for academic performance. Journal of Counseling Psychology, 62, 718-731. doi: 10.1037/cou0000097

Rice, K. G., \& Richardson, C. M. E. (2014). Classification challenges in perfectionism. Journal of Counseling Psychology, 61, 641-648. doi: 10.1037/cou0000040

Rosenberg, M. (1979). Conceiving the self. New York: Basic Books.

Ryan, R. M. (1982). Control and information in the intrapersonal sphere: An extension of cognitive evaluation theory. Journal of Personality and Social Psychology, 43, 450-461.

Ryan, R. M., Bernstein, J. H., \& Brown, K. W. (2010). Weekends, work, and well-being: Psychological need satisfactions and day of the week effects on mood, vitality, and physical symptoms. Journal of Social and Clinical Psychology, 29, 95-122.

Ryan, R. M., \& Deci, E. L. (2017). Self-Determination Theory: Basic psychological needs in motivation, development, and wellness. New York: Guilford Press.

Ryan, R. M., Koestner, R., \& Deci, E. L. (1991). Ego-involved persistence: When free-choice behavior is not intrinsically motivated. Motivation and Emotion, 15, 185-205.

Schultheiss, O. C., \& Brunstein, J. C. (2005). An implicit motive approach to competence. In A. 
J. Elliot \& C. S. Dweck (Eds.), Handbook of competence and motivation (pp. 31-51). New York: Guilford.

Sheldon, K. M., \& Gunz, A. (2009). Psychological needs as basic motives, not just experiential requirements. Journal of Personality, 77, 1467-1492. doi: 10.1111/j.14676494.2009.00589.x

Schüler, J., Sheldon, K. M., \& Fröhlich, S. M. (2010). Implicit need for achievement moderates the relationship between competence need satisfaction and subsequent motivation. Journal of Research in Personality, 44, 1-12. doi: 10.1016/j.jrp.2009.09.002

Schüler, J., Sheldon, K. M., Prentice, M., \& Halusic, M. (2016). Do some people need autonomy more than others? Implicit dispositions toward autonomy moderate the effects of felt autonomy on well-being. Journal of Personality, 84, 5-20. doi: 10.1111/jopy.12133

Slabbinck, H., De Houwer, J., \& Van Kenhove, P. (2011). A pictorial attitude IAT as a measure of implicit motives. European Journal of Personality, 25, 76-86. doi: 10.1002/per.778

Soenens, B., \& Duriez, B. (2012). Does conservatism have a self-esteem enhancing function? An examination of associations with contingent self-worth and ill-being in late adults. Personality and Individual Differences, 52, 728-732. doi: 10.1016/j.paid.2011.12.037

Soenens, B., Vansteenkiste, M., Luyten, P., Duriez, B., \& Goossens, L. (2005). Maladaptive perfectionistic self-representations: The mediational link between psychological control and adjustment. Personality and Individual Differences, 38, 487-498. doi:10.1016/j.paid.2004.05.008

Spruyt, A., Clarysse, J., Vansteenwegen, D., Baeyens, F., \& Hermans, D. (2010). Affect 4.0: A free software package for implementing psychological and psychophysiological experiments. Experimental Psychology, 57, 36-45. doi: 10.1027/1618-3169/a000005

Stoeber, J., Chesterman, D., \& Tarn, T. A. (2010). Perfectionism and task performance: Time on 
task mediates the perfectionistic strivings-performance relationship. Personality and Individual Differences, 48, 458-462. doi: 10.1016/j.paid.2009.11.021

Tafarodi, R. W., \& Swann, W. B. (1995). Self-liking and self-competence as dimensions of global self-esteem: Initial validation of a measure. Journal of Personality Assessment, 65, 322-342. doi: 10.1207/s15327752jpa6502_8

Thrash, T. M., \& Elliot, A. J. (2002). Implicit and self-attributed achievement motives: Concordance and predictive validity. Journal of Personality, 70, 729-756.

Thrash, T. M., Maruskin, L. A., \& Martin, C. C. (2012). Implicit-explicit motive congruence. In R. M. Ryan (Ed.), The Oxford Handbook of Human Motivation (pp. 141-156). New York: Oxford university press.

Vahey, N. A., Barnes-Holmes, D., Barnes-Holmes, Y., \& Stewart, I. (2009). A first test of the implicit relational assessment procedure as a measure of self-esteem: Irish prisoner groups and university students. Psychological Record, 59, 371-387.

Van Assche, J., Van der Kaap-Deeder, J., Audenaert, E., De Schryver, M., \& Vansteenkiste, M. (in press). Are the benefits of autonomy satisfaction and the costs of autonomy frustration dependent on individuals' autonomy strength? Journal of Personality.

Van den Broeck, A., Vansteenkiste, M., De Witte, H., Soenens, B., Lens, W. (2010). Capturing autonomy, competence, and relatedness at work: Construction and initial validation of the Work-related Basic Need Satisfaction scale. Journal of Occupational and Organizational Psychology, 83, 981-1002. doi: 10.1348/096317909X481382

Van der Kaap-Deeder, J., Wouters, S., Verschueren, K., Briers, V., Deeren, B., \& Vansteenkiste, M. (2016). The pursuit of self-esteem and its motivational implications. Psychologica Belgica, 56, 143-168. doi: 10.5334/pb.277

Verstuyf, J., Vansteenkiste, M., Soenens, B., Boone, L., \& Mouratidis, A. (2013). Daily ups and 
downs in women's binge eating symptoms: The role of basic psychological needs, general self-control and emotional eating. Journal of Social and Clinical Psychology, 32, 335361. doi: 10.1521/jscp.2013.32.3.335

Wang, C. K., Liu, W. C., Lochbaum, M. R., \& Stevenson, S. J. (2009). Sport ability beliefs, 2 X 2 achievement goals, and autonomy: The moderating role of perceived competence in the exercise domain. Research Quarterly for Exercise and Sport, 80, 303-312.

White, R. W. (1959). Motivation reconsidered: The concept of competence. Psychological Review, 66, 297-333. doi: 10.1037/h0040934 


\section{Footnotes}

1. Across the studies, we also assessed implicit self-esteem. However, due to a low reliability of this measure, we did not obtain any meaningful results. Hence, implicit selfesteem will not be discussed further.

2. To see whether the order of the IATs would make a difference with respect to the correlations between these IATs and other constructs as reported in Table 3, we reran these analyses with data either from participants who completed the competence need satisfaction IAT first or from participants who completed the competence need desire IAT first. There were no relevant differences between these correlations and the correlations reported in Table 3.

3. We repeated the main analyses while including the IRAP data of individuals who met the criteria on at least two sets of test blocks (rather than all). These results were similar to those obtained with the more strict criteria.

4. In addition to the overall $D$-IRAP score, we also calculated four trial type-specific $D$ IRAP scores, one for each of the relations assessed by the satisfaction or desire IRAP (e.g., "I am" + “competent", "I am not" + “competent", "I am" + "incompetent" and "I am not" + "incompetent"). Analyses with these four specific $D$-IRAP scores were similar to those obtained with the overall $D$-IRAP score.

5. To see whether the order of the IRAPs would make a difference with respect to the correlations between these IRAPs and other constructs as reported in Table 4, we reran these analyses with data either from participants who completed the competence need satisfaction IRAP first or from participants who completed the competence need desire IRAP first. There were no relevant differences between these correlations and the 
correlations reported in Table 4, with one exception. That is, there was a positive relation between the competence need desire IRAP and self-esteem for those participants who first completed the competence need desire IRAP $(r=.34, p<.10)$, whereas these variables were unrelated for participants who first completed the competence need satisfaction $\operatorname{IRAP}(r=-.12, p>.05)$.

6. In addition to the average $D$-IRAP score based on the first two trial types, we also calculated two trial type-specific $D$-IRAP scores (i.e., "I am" + "competent" and "I am" + "incompetent"). Analyses with these two specific $D$-IRAP scores were similar to those obtained with the overall $D$-IRAP score.

7. We redid the main analyses using the IRAP data of those individuals who fulfilled the criteria on at least two sets of (rather than all) test blocks. These results were similar to those obtained with the more strict criteria.

8. To see whether the order of the IAT and IRAP would make a difference with respect to the correlations between these implicit measures and other constructs as reported in Table 6 , we reran these analyses with data either from participants who completed the IAT first or from participants who completed the IRAP first. There were no relevant differences between these correlations and the correlations reported in Table 6 . 
Table 1

Overview of the Characteristics of each Study

\begin{tabular}{|c|c|c|c|c|}
\hline & Study 1 & Study 2 & Study 3 & Study 4 \\
\hline Nr. participants & 62 & 67 & 103 & 72 \\
\hline \multicolumn{5}{|l|}{ Sociodemographic characteristics } \\
\hline$\%$ female & $85.48 \%$ & $79.10 \%$ & $85.44 \%$ & $70.83 \%$ \\
\hline Mage (SDage) & $18.92(2.49)$ & $22.13(4.26)$ & $22.59(4.98)$ & $19.54(3.92)$ \\
\hline \multicolumn{5}{|l|}{ Implicit measures } \\
\hline Competence need satisfaction & IAT & IRAP I & IAT, IRAP II & IAT \\
\hline Competence need desire & IAT & IRAP & - & - \\
\hline \multicolumn{5}{|l|}{ Constructs nomological network } \\
\hline Explicit competence need satisfaction & $\mathrm{X}$ & $X$ & $\mathrm{X}$ & $\mathrm{X}$ \\
\hline Explicit competence need desire & $\mathrm{X}$ & $\mathrm{X}$ & & \\
\hline Perfectionism & $X$ & $\mathrm{X}$ & $X$ & \\
\hline Self-esteem & $X$ & $X$ & $\mathrm{X}$ & $X$ \\
\hline Contingent self-esteem & $X$ & $X$ & $X$ & \\
\hline Others, namely... & Grades & & $\begin{array}{c}\text { Task performance } \\
\text { Task-related } \\
\text { competence }\end{array}$ & $\begin{array}{l}\text { Task-related } \\
\text { competence }\end{array}$ \\
\hline Design & $\begin{array}{l}\text { Correlational; } \\
\text { known-groups } \\
\text { approach }\end{array}$ & Correlational & Experimental & Experimental \\
\hline Hypotheses & $1,2,3,4$ & $1,2,3,4$ & $1,2,3,5,6$ & $1,2,3,5$ \\
\hline
\end{tabular}


Note. IRAP I, referring to the IRAP used in Study 2, involved the response rules: (1) "Please respond as if I am competent and I am not incompetent" and (2) "Please respond as if I am incompetent and I am not competent".

IRAP II, referring to the IRAP used in Study 3, involved the response rules: (1) "Please respond as if you think that you are competent and others think that you are incompetent" and (2) "Please respond as if you think that you are incompetent and others think that you are competent". 


\section{Table 2}

Comparison of the Means between the Personal Standards and Evaluative Concerns Perfectionistic Groups (Study 1)

\begin{tabular}{|c|c|c|c|c|}
\hline & $\begin{array}{l}\text { Personal standards } \\
\text { perfectionistic group } \\
(N=32)\end{array}$ & $\begin{array}{l}\text { Evaluative concerns } \\
\text { perfectionistic group } \\
(N=30)\end{array}$ & Comparison grou & \\
\hline & $M(S D)$ & $M(S D)$ & $F$-value & $\eta^{2}$ \\
\hline \multicolumn{5}{|l|}{ Perfectionism dimensions } \\
\hline Personal standards & $3.25(.51)$ & $3.58(.55)$ & $F(1,60)=5.86^{*}$ & .09 \\
\hline Evaluative concerns & $2.29(.50)$ & $3.04(.51)$ & $F(1,60)=34.00 * * *$ & .36 \\
\hline \multicolumn{5}{|l|}{ Implicit measures (IATs) } \\
\hline Competence need satisfaction & $.88(.25)$ & $.83(.27)$ & $F(1,60)=.50$ & .01 \\
\hline Competence need desire & $.88(.21)$ & $1.00(.22)$ & $F(1,60)=5.16^{*}$ & .08 \\
\hline \multicolumn{5}{|l|}{ Explicit measures } \\
\hline Competence need satisfaction & $3.75(.57)$ & $3.03(.69)$ & $F(1,59)=18.84 * * *$ & .24 \\
\hline Competence need desire & $3.27(.81)$ & $3.85(.80)$ & $F(1,59)=7.94^{* *}$ & .12 \\
\hline
\end{tabular}

Note. IAT = Implicit Association Test. Eta-squared $\left(\eta^{2}\right)$ is a measure of effect size.

$* p<.05 . * * p<.01 . * * * p<.001$ 
Table 3

Descriptives and (Partial) Correlations between Study Variables (Study 1)

\begin{tabular}{|c|c|c|c|c|c|c|c|}
\hline & $M$ & $S D$ & 1a & $1 \mathrm{~b}$ & 2 & 3 & 4 \\
\hline 1. Competence need satisfaction IAT & 0.86 & 0.26 & - & & & & \\
\hline 2. Competence need desire IAT & 0.94 & 0.22 & .05 & - & - & & \\
\hline 3. Explicit competence need satisfaction (C) & 3.40 & 0.72 & $.31 *$ & - & -.07 & - & \\
\hline 4. Explicit competence need desire & 3.55 & 0.85 & -.19 & - & -.08 & $-.64 * * *$ & - \\
\hline 5. Self-esteem & 1.84 & 0.49 & $.34 * *$ & .17 & -.19 & $.68 * * *$ & $-.52 * * *$ \\
\hline 6. Contingent self-esteem & 3.75 & 0.39 & $-.35 * *$ & -.24 & .04 & $-.50 * * *$ & $.46^{* * *}$ \\
\hline 7. Grades & 11.71 & 3.23 & .00 & -.15 & -.06 & $.32 *$ & -.15 \\
\hline
\end{tabular}

Note. Whereas 1a refers to the analyses without controlling for explicit competence need satisfaction, $1 \mathrm{~b}$ refers to the partial correlations controlling for explicit competence need satisfaction.

IAT $=$ Implicit Association Test. $\mathrm{C}=$ Composite score with satisfaction items and reversed frustration-related items.

$* p<.05 . * * p<.01 . * * * p<.001$ 


\section{Table 4}

Descriptives and (Partial) Correlations between Study Variables (Study 2)

\begin{tabular}{|c|c|c|c|c|c|c|c|}
\hline & $M$ & $S D$ & $1 \mathrm{a}$ & $1 \mathrm{~b}$ & 2 & 3 & 4 \\
\hline 1. Competence need satisfaction IRAP & 0.14 & 0.20 & - & & - & & \\
\hline 2. Competence need desire IRAP & 0.16 & 0.20 & $.37 * *$ & - & - & & \\
\hline 3. Explicit competence need satisfaction (C) & 3.54 & 0.59 & -.07 & - & .10 & - & \\
\hline 4. Explicit competence need desire & 3.63 & 0.74 & .16 & - & .12 & -.14 & - \\
\hline 5. PS perfectionism & 3.06 & 0.71 & .12 & .09 & .05 & .04 & .08 \\
\hline 6. EC perfectionism & 2.50 & 0.58 & .15 & .11 & .08 & $-.45 * * *$ & .12 \\
\hline 7. Self-esteem & 2.00 & 0.38 & .03 & .13 & .10 & $.72 * * *$ & -.17 \\
\hline 8. Contingent self-esteem & 3.59 & 0.59 & -.22 & -.26 & -.11 & -.19 & .06 \\
\hline
\end{tabular}

Note. Whereas 1a refers to the analyses without controlling for explicit competence need satisfaction, $1 \mathrm{~b}$ refers to the partial correlations controlling for explicit competence need satisfaction.

IRAP = Implicit Relational Assessment Procedure. $\mathrm{C}=$ Composite score with satisfaction items and reversed frustration-related items. $\mathrm{PS}=$ Personal standards. $\mathrm{EC}=$ Evaluative concerns.

$* * p<.01 . * * * p<.001$. 


\section{Table 5}

Comparison of the Means between the Competence Need Satisfaction and the Competence Need Frustration Condition (Study 3)

\begin{tabular}{|c|c|c|c|c|}
\hline & Satisfaction condition & Frustration condition & Comparison betwee & ons \\
\hline & $M(S D)$ & $M(S D)$ & $F$-value & $\eta^{2}$ \\
\hline Competence need satisfaction IAT & $0.85(0.35)$ & $0.79(0.34)$ & $F(1,93)=0.48$ & .01 \\
\hline Competence need satisfaction IRAP & $0.30(0.26)$ & $0.15(0.19)$ & $F(1,70)=7.09 *$ & .09 \\
\hline State explicit competence need satisfaction (C) & $3.69(0.67)$ & $3.74(0.65)$ & $F(1,93)=0.19$ & .00 \\
\hline State PS perfectionism & $2.87(0.72)$ & $3.03(0.85)$ & $F(1,93)=0.98$ & .01 \\
\hline State EC perfectionism & $2.39(0.67)$ & $2.33(0.66)$ & $F(1,93)=0.14$ & .00 \\
\hline State self-esteem & $3.06(0.47)$ & $3.08(0.40)$ & $F(1,93)=0.02$ & .00 \\
\hline State contingent self-esteem & $3.54(0.46)$ & $3.54(0.60)$ & $F(1,93)=0.02$ & .00 \\
\hline Letter detection task & $0.07(0.02)$ & $0.06(0.02)$ & $F(1,93)=2.07$ & .02 \\
\hline Task-related competence & $4.23(0.97)$ & $3.61(0.96)$ & $F(1,93)=9.44^{* *}$ & .09 \\
\hline
\end{tabular}

Note. IAT = Implicit Association Test. $\mathrm{C}=$ Composite score with satisfaction items and reversed frustration-related items. $\mathrm{PS}=$

Personal standards. $\mathrm{EC}=$ Evaluative concerns. Eta-squared $\left(\eta^{2}\right)$ is a measure of effect size.

$* p<.05 . * * p .01$ 
Table 6

Descriptives and (Partial) Correlations between Study Variables (Study 3)

\begin{tabular}{|c|c|c|c|c|c|c|c|}
\hline & $M$ & $S D$ & $1 \mathrm{a}$ & $1 b$ & $2 \mathrm{a}$ & $2 b$ & 3 \\
\hline 1. Competence need satisfaction IAT & 0.80 & 0.35 & - & & & & \\
\hline 2. Competence need satisfaction IRAP & 0.22 & 0.24 & .06 & - & - & - & \\
\hline 3. State explicit competence need satisfaction (C) & 3.70 & 0.66 & $.27 * *$ & - & .19 & - & - \\
\hline 4. State PS perfectionism & 2.94 & 0.80 & .14 & .18 & .03 & .06 & -.08 \\
\hline 5. State EC perfectionism & 2.36 & 0.65 & -.12 & .04 & $-.28 *$ & $-.24 *$ & $-.57 * * *$ \\
\hline 6. State self-esteem & 3.06 & 0.43 & $.22 *$ & .04 & .15 & .04 & $.73 * * *$ \\
\hline 7. State contingent self-esteem & 3.52 & 0.53 & -.03 & .02 & -.08 & -.09 & -.18 \\
\hline 8. Letter detection task & 0.06 & 0.02 & .18 & .18 & .12 & .13 & .03 \\
\hline 9. Task-related competence & 3.94 & 0.99 & .09 & .04 & .10 & .07 & .18 \\
\hline
\end{tabular}

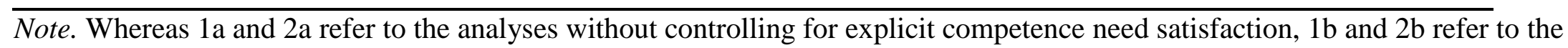
partial correlations controlling for explicit competence need satisfaction.

IAT $=$ Implicit Association Test. IRAP = Implicit Relational Assessment Procedure $\mathrm{C}=$ Composite score with satisfaction items and reversed frustration-related items. PS = Personal standards. EC = Evaluative concerns.

$* p<.05 . * * p<.01 . * * * p<.001$. 
Table 7

Comparison of the Means between the Competence Need Satisfaction and the Competence Need Frustration Condition (Study 4)

\begin{tabular}{lcccc}
\hline & Satisfaction & Frustration & Comparison between conditions \\
& condition & condition & & \\
& $(N=36)$ & $(N=36)$ & & \\
\hline & $M(S D)$ & $M(S D)$ & $F(1,63)$-value & $\eta^{2}$ \\
\hline Competence need satisfaction IAT & $0.73(0.31)$ & $0.84(0.27)$ & 2.35 & .03 \\
Puzzle task-related competence & $3.97(1.24)$ & $1.74(0.95)$ & $67.27 * * *$ & .49 \\
State explicit competence need satisfaction $(\mathrm{C})$ & $3.37(0.58)$ & $3.33(0.65)$ & 0.04 & .00 \\
State self-esteem & $7.53(1.23)$ & $7.24(1.45)$ & 0.64 & .01
\end{tabular}

Note. IAT = Implicit Association Test. $\mathrm{C}=$ Composite score with satisfaction items and reversed frustration-related items. Eta-squared $\left(\eta^{2}\right)$ is a measure of effect size.

$* * * p<.001$ 
Table 8

Descriptives and (Partial) Correlations between Study Variables (Study 4)

\begin{tabular}{lccccc}
\hline & $M$ & $S D$ & $1 \mathrm{a}$ & $1 \mathrm{~b}$ & 2 \\
\hline 1. Competence need satisfaction IAT & 0.79 & 0.29 & - & - & - \\
2. Puzzle task-related competence & 2.78 & 1.57 & -.12 & - & .14 \\
3. State explicit competence need satisfaction (C) & 3.40 & 0.64 & .19 & - & .03 \\
4. State self-esteem & 7.43 & 1.34 & .09 & -.03 & $.77^{* * *}$ \\
\hline
\end{tabular}

Note. Whereas 1a refers to the analyses without controlling for explicit competence need satisfaction, $1 \mathrm{~b}$ refers to the partial correlations controlling for explicit competence need satisfaction.

IAT $=$ Implicit Association Test. C = Composite score with satisfaction items and reversed frustration-related items.

$* * * p<.001$. 